See discussions, stats, and author profiles for this publication at: https://www.researchgate.net/publication/273640025

\title{
One Special Question to Start with: Can HIF/NFkB be a Target in Inflammation?
}

Article $\cdot$ March 2015

DOI: 10.2174/1871530315666150316120112 · Source: PubMed

CITATIONS

9 authors, including:

Matteo A Russo

Sapienza University of Rome

230 PUBLICATIONS 7,755 CITATIONS

SEE PROFILE

8. Ilaria Carnevale

14 PUBLICATIONS 127 CITATIONS

SEE PROFILE

Some of the authors of this publication are also working on these related projects:

HIF/NFkB axis activation in human chronic diseases View project

$\mathrm{Na} / \mathrm{K}$-ATP-ase Indipendent Cell volume control View project
READS

356

Luigi Sansone

Istituto di Ricovero e Cura a Carattere Scientifico San Raffaele Pisana

10 PUBLICATIONS 179 CITATIONS

SEE PROFILE

Federica Limana

Istituto di Ricovero e Cura a Carattere Scientifico San Raffaele Pisana

40 PUBLICATIONS 7,564 CITATIONS

SEE PROFILE 


\title{
One Special Question to Start with: Can HIF/NFkB be a Target in Inflammation?
}

\author{
Matteo A. Russo ${ }^{1, *}$, Luigi Sansone ${ }^{1}$, Ilaria Carnevale ${ }^{1,2}$, Federica Limana ${ }^{1}$, Alessandra Runci ${ }^{1,2}$, \\ Lucia Polletta ${ }^{2}$, Giulietta A. Perrone ${ }^{3}$, Elena De Santis ${ }^{2}$ and Marco Tafani ${ }^{1,2}$
}

${ }^{1}$ Laboratory of Molecular and Cellular Pathology, IRCCS San Raffaele Pisana, Rome, Italy; ${ }^{2}$ Department of Experimental Medicine, Sapienza University of Rome, Rome, Italy; ${ }^{3}$ UOC of Pathologic Anatomy, San Filippo Neri Hospital, Rome, Italy

\begin{abstract}
Hypoxia and Inflammation are strictly interconnected with important consequences at clinical and therapeutic level. While cell and tissue damage due to acute hypoxia mostly leads to cell necrosis, in chronic hypoxia, cells that are located closer to vessels are able to survive adapting their phenotype through the expression of a number of genes, including proinflammatory receptors for alarmins. These receptors are activated by alarmins released by necrotic cells and generate signals for master transcription factors such as NFkB, AP1, etc. which control hundreds of genes for innate immunity and damage repair. Clinical consequences of chronic inflammatory reparative response activation include cell and tissue remodeling, damage in the primary site and, the systemic involvement of distant organs and tissues.

Thus every time a tissue environment becomes stably hypoxic, inflammation can be activated followed by chronic damage and cell death or repair with vessel proliferation and fibrosis. This pathway can occur in cancer, myocardial infarction and stroke, diabetes, obesity, neurodegenerative diseases, chronic and autoimmune diseases and age-related diseases. Interestingly, proinflammatory gene expression can be observed earlier in hypoxic tissue cells and, in addition, in activated resident or recruited leukocytes.

Herewith, the reciprocal relationships between hypoxia and inflammation will be shortly reviewed to underline the possible therapeutic targets to control hypoxia-related inflammation in a number of epidemiologically important human diseases and conditions.
\end{abstract}

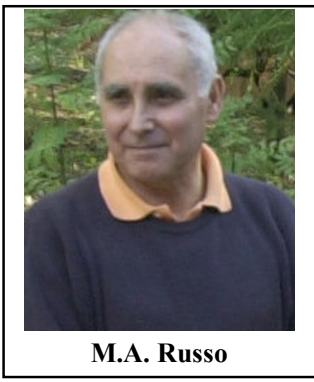

Keywords: Hypoxia, Inflammation, Tissue and cell repair, Molecular rehabilitation, Stress response

\section{HYPOXIA AND ADAPTATION TO HYPOXIA}

Hypoxia is a reduction of normal level of tissue oxygen tension, occurring for several reasons in some physiological processes such as early embryonic growth or stem cell niche maintenance [1] and in a number of pathological conditions such as infarction, tumors, diabetes, obesity, pathological hypertrophy, neurodegenerative diseases and many others [1].

Hypoxia has two effects: 1-necrosis of cells in the region more distant from tissue vessels. 2-adaptation of cells in the region along the hypoxic gradient close to the vessels. Necrosis: the $\mathrm{O}_{2}$ shortage causes inhibition of ATP production, rapid fall of the energy charge, and loss of ionic gradients with the alteration of cytosolic calcium homeostasis $[2,3]$. The increase of cytosolic $\mathrm{Ca}^{++}$concentration above $10^{-6} \mathrm{M}$, dramatically activates the peroxidative metabolism [2], an irreversible contraction and degradation of the cytoskeleton $[3,4]$ and the activation of $\mathrm{Ca}^{++}$-dependent cytosolic proteases (calpains) and DNA-ases [5,6], all leading to a rapid and irreversible cell degradation. Plasmamembrane rupture

*Address correspondence to this author at the Laboratory of Molecular and Cellular Pathology, IRCCS San Raffaele Pisana, Via di Val Cannuta, 247 - 00166 Rome, Italy; Tel: +39-06-52255668; Fax: +39-06-52253701;

E-mails: matteoantonio.russo@uniroma1.it Or matteo.russo@sanraffaele.it due to lipoperoxidation is responsible for the definitive loss of the ionic gradients and for the release of intracellularly segregated molecules, many of which are called alarmins for their ability to signal the cell damage to specific receptors on adjacent cells. Adaptation of cells surviving to the hypoxia (when they are closer to the vessels) occurs through the activation of HIF $1 \alpha$ and the expression of a number of genes, such as VEGF, Glut1 and HKII, TERT [7], stemness genes and, very importantly in our case, endogenous alarmin receptors, such as RAGE, P2X7 [8], Toll-like receptors [9], NOD-like receptors [10], etc. (Fig. 1). The beneficial effects of these genes can be observed in multiple cell or tissue functions and include: vasodilatation and neoangiogenesis to increase the local blood supply, metabolic shift from oxidative mitochondrial metabolism to anaerobiotic glycolysis, activation of telomerase in stem cells, reprogramming somatic cells to stem cells [11].

Importantly, alarmins (Table 1) released by necrotic cells (HMGB1, ATP/ADP, membrane debris, nucleic acids, etc.) bind their receptors and activate NFkB with the expression of hundreds of genes of the inflammatory reparative response (IRR) [for ref. see Table 1]. Therefore, non leukocytic cells in hypoxic tissue microenvironment can present a NFkB-dependent proinflammatory gene response similar to that seen in activated leukocytes (Fig. 1). 


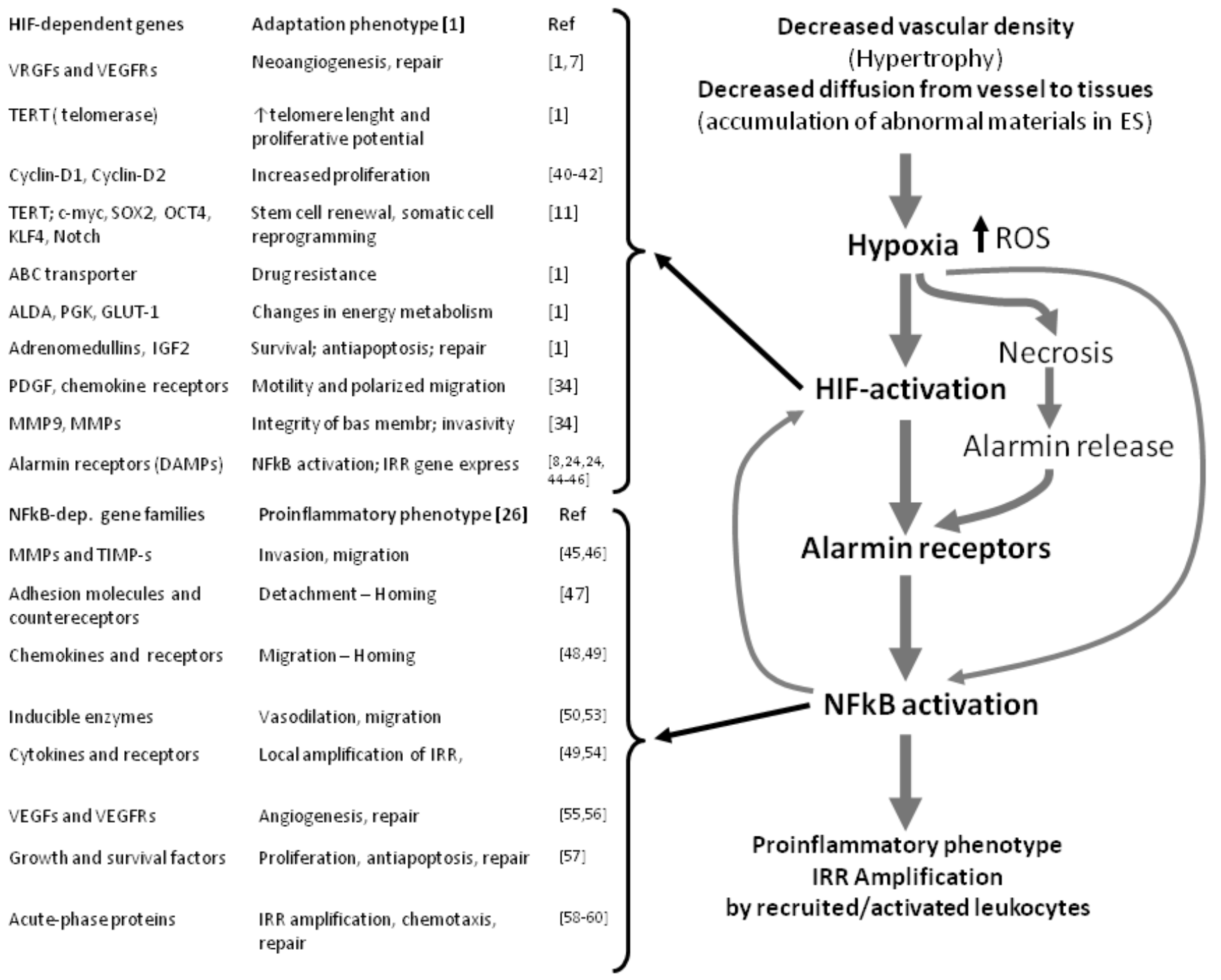

Fig. (1). Bridging hypoxia and inflammation in some human chronic diseases. HIF/NFkB-directed gene expression and phenotype remodeling. For HIF-directed adaptation, only representative genes are indicated. For NFkB, activated genes can vary depending on cell/tissue, therefore, for simplicity, we have indicated only the involved gene family. Representative references are indicated. Alternative pathways for hypoxia-associated NFkB activation and NFkB-dependent HIF activation are indicated.

\section{INFLAMMATION OR INNATE DEFENSIVE AND REPARATIVE RESPONSE (IRR)}

Inflammation is a tissue/cell response to a noxious agent and/or to a cell damage to protect, defend, repair and limit the harm of the organism. Acute inflammation was already well known to Hyppocrates and thereafter precisely described by Galeno as acute phenomenon with prevalent vascular involvement. The modern picture is more complex and detailed due to the knowledge of pathways and molecular players for its local activation, specific tissue reactions, production of effectors, recruitment of distant cells, systemic involvement, production of damage, fine tuning regulation, and inhibition of progression for resolution and repair.

IRR may result inadequate (that is ineffective in protecting and repairing), chronic (that is prolonged), inopportune (when activated untimely and awkwardly), excessive (when is not rightly controlled) during one or all its phases [12]. In these situations IRR is clinically chronic and contributes substantially to host damages, causing multiorgan dysfunctions. In the progression of IRR it is possible to recognize typical signs and symptoms such as the accumulation of exudate, fever, leukocyte infiltration, excess of ROS production, damage to surrounding tissue, and a continuous fibrotic repair which leads to fibrosis and to organ insufficiency [12].

Inflammation is triggered by exogenous damaging agents such as viruses, bacteria, fungi, other pathogens and extraneous agents, presenting on their surface characteristic chemical pattern (Pathogen-Associated Molecular Patterns or PAMPs), or by endogenous signals (Damage-Associated Molecular Patterns or DAMPs) [13], which are usually released by damaged cells (necrosis, membrane shedding, exosomes, apoptosis) (Table 1). Collectively PAMPs and DAMPs are also known as alarmins [14-22]. These 
Table 1. Alarmins and their receptors activating inflammation.

\begin{tabular}{|c|c|c|}
\hline Exogenous Alarmins (PAMPs) & Receptors (Ref. 12, 13, 59) & References \\
\hline \hline - Viruses & TLR3, TLR7, TLR8, TLR9 & {$[13,59]$} \\
\hline - Bacteria & CD14, TLR2, TLR4, TLR5, TLR9, TLR11 & [13, 59] \\
\hline - Fungi and protozoa & TLR2, TLR4, others & {$[13,59]$} \\
\hline - Obligate Intracellular pathogens & NOD-like receptors (NLRs) and intracellular TLRs & [19, 58] \\
\hline -Intracellular fibers (such as asbestos fibers) & NOD-like receptors (NLRs) & [19, 20] \\
\hline Endogenous alarmins & Receptors & [12,55] \\
\hline HMGB1 & P2X7, (other P2X and P2Y receptors?) & [55, 56] \\
\hline ATP/ADP & TLRs (?) & [57] \\
\hline Oxidized phospholipids and Phosphatidyl-serine Pattern & NOD-like receptors (NLRs) and intracellular TLRs (TLR2, TLR4, CD14) & [19] \\
\hline Crystals (cholesterol, uric acid, etc.) & RIG-like helicases (RLHs), TLR9 \\
\hline dsDNA - dsRNA virali citosolici & TLR4+CCR6, and FPRL1 & [55] \\
\hline Defensins and cathelicidins & CD14, CD91, TLR2, TLR4, CD40 \\
\hline Heat shock proteins & {$[55]$} \\
\hline
\end{tabular}

References are indicated and discussed in the text. PAMPs = pathogen associated molecular patterns; DAMPs = damage associated molecular patterns; TLRs = Toll-like receptors; CCR6 $=$ chemokine receptor $6 ;$ FRLP1 = formyl peptide receptor-like 1.

pleomorphic molecules activate, with different specificity, a number of receptors belonging to highly conserved families with diverse signaling pathways, converging in the activation of NFkB, AP-1 and other TFs which are recognized as the major players in the inflammation, controlling all the genes participating to this response $[13,23]$.

Alarmin receptors (ARs) were firstly localized in tissue resident leukocytes $[13,14]$, but at present have been described in many other cells and tissues [13]. In fact, there are evidences that alarmin receptors can be induced and expressed de novo in resident or recruited stem cells and pluripotent undifferentiated progenitors from many tissues, under stressing conditions such as acute or chronic hypoxia [24] and cellular ROS increase [25, 26]. ARs after sensing alarmins generate a signal cascade that activates NFkB (or other TFs), leading to the expression of genes belonging to the large families of the IRR, all involved in defence, protection and repair of cell and tissues (Table 1).

Another molecular component of the innate response is inflammasome constituted by large protein complexes assembled by cytosolic alarmin receptors (NOD-like receptors or NLRs) activated into the cytosol [27, 28]. While surface membrane alarmin receptors interact with signals coming from extracellular space (of exogenous origin or released by damaged cells), inflammasomes are activated by intracellular molecules already present in damaged, stressed or aged cells. Examples of these molecules include monosodium urate crystals (gout), cholesterol crystals (hypercholesterolemia and atherosclerosis), islet amyloid polypeptide (stored in the pancreatic beta cells in type 2 diabetes) [28], viral and bacterial DNA and simpler molecules such as ATP, HMGB1 and membrane phosphatidylserine which become available in damaged or dying cells as membrane debris. Activated NLRs respond rapidly to different cytosolic PAMPs and DAMPs, recruiting and activating pro-caspase-1 and other pro-inflammatory caspases [27]. Caspase-1 activates the major proinflammatory cytokines (IL-1 and IL-18) and is also responsible for degradation of many target proteins, contributing to cell degradation [19, 27]. Defects in the structure and activity of inflammasomes can be responsible for a large number of chronic human diseases, including chronic arthritis, Crohn's disease, irritable bowel and other inflammatory diseases, diabetes, metabolic syndrome, cancer and ageing $[12,19,29,30]$. Targeting these proteins represents an additional new therapeutic strategy for these pathologies $[12,31]$.

\section{Effectors and Cytokine Storm}

Inflammation or innate immunity involve signaling pathways leading to the production of inflammatory mediators or effectors in a cell-specific manner. Examples are classical mediators such as histamine, prostaglandins, leukotrienes, lipoxins, plasmalogens, cytokines, chemokines, reactive oxygen intermediates (ROI), reactive nitrogen intermediates (RNI), and anti-inflammatory molecules (IL-10, A20, IL-1RA). Sometimes a massive production of proinflammatory cytokines (cytokine storm) occurs leading to multiorgan irreversible damage and shock [1, 31]. As a matter of fact, all the effectors are a double-edge sword, having from one side an exquisite protective role to defeat invaders and limiting the harm of the host, from the other hand when their action is excessive or improper they can be the driving force responsible for tissue/organ damages. During inflammation a production of numerous ROI, RNI and chlorine species occurs, in addition to the products of lipid and sugar oxidation $[32,33]$. Most of these products are capable of chemically modifying protein amino acids, changing the structure, folding and function of proteins. Increasing evidence demonstrates that such oxidative post- 
translational modifications may generate neo-epitopes capable of eliciting both innate and adaptive immune responses giving origin to autoimmune diseases such as systemic lupus erythematosus, rheumatoid arthritis, chronic bowel diseases and others [25]. Some new epitopes generated by oxidation are conserved along evolution as pathogen-associated molecular patterns (PAMPs) [25].

\section{IRR Regulation}

Usually inflammatory response is self-limiting and well controlled, but in the presence of improper activation, aberrant amplification, mutated alarmin receptors or inflammasomes, inhibited or delayed resolution results in chronic diseases. Much attention has been focused on proinflammatory signaling but the precise mechanisms leading to the inhibitory control of inflammation is still unclear [34].

The IkB kinase (IKK) complex contains two catalytic subunits, IKK $\alpha$ and IKK $\beta$, and controls the activation of NFkB transcription factors, the pivotal actor/controller of the inflammation [34, 35]. NFkB activation and activity persistence are tightly controlled by a number of endogenous mechanisms that limit the excessive and prolonged production of pro-inflammatory mediators and the associated tissue damage [35].

NFkB (nuclear factor $\mathbf{k B}$ ) is a transcription factor that controls and modulates the expression of genes involved in both the innate and adaptive immune response [34]. The regulatory ability of $\mathrm{NFkB}$ is controlled by posttranscriptional modifications such as phosphorylation and complex interactions with other cytosolic and nuclear proteins. Upon activation of the NFkB signaling pathway, IkB kinases target IkBs for degradation. This allows NFkB to translocate and accumulate in the nucleus, where it binds to DNA, resulting in the expression of target genes [34-36]. One of the genes activated by NFkB is that encoding IkB. Newly synthesized IkB binds to NFkB and attenuates the pathway of response to alarmin receptors, thereby creating a negative feedback loop within this signaling pathway [35]. SOCS gene family is another major regulator of IRR once activated. Seven SOCS members have been identified but in particular SOCS-1 inhibits the cytokine signaling via Janus kinase (JAK) and STAT, efficiently negatively regulating NFkB-directed proinflammatory expression.

Most of the times, the IRR starts locally at the damaged site, and then rapidly eliminate the invading pathogen and/or repair the damaged cell and tissues. However, if the local activation is strong and the release of mediators (such as eicosanoids and cytokines) is abundant, distant leukocytes and cells are recruited, thus amplifying the response at systemic level. The necrosis of damaged tissues, such as in hypoxic tumours, contributes to the IRR amplification further activating resident leukocytes and recruiting the peripheral ones $[37,38]$.

In summary IRR is a complex response to a pathogen or to a cell damage in which inflammatory cells (chiefly leukocytes and endothelial cells, but also tissue cells) are activated and express a specific set of genes named "proinflammatory genes" acting to defend against pathogens, protecting and repairing damaged cells. Proinflammatory gene expression has been observed also in hypoxic tissue cells, especially stem cells and less differentiated progenitors, and appears basically similar to that of activated leukocytes.

\section{HYPOXIA AND INFLAMMATION IN HUMAN PATHOLOGY}

A large number of evidences suggest that when a tissue environment becomes stably hypoxic, inflammation can be activated causing chronic damage and cell death as well as repair with vessel proliferation and fibrosis. This pathway, with some variations, can occur in many important human pathologies such as cancer, infarction, diabetes, obesity, pathologic hypertrophy, neurodegenerative diseases, chronic and autoimmune diseases and age-related diseases. Interestingly, both HIF-dependent adaptation and proinflammatory gene expression can be observed very early in these conditions and have been shown more evidently in local hypoxic stem cells and progenitors [39].

In the next paragraphs a rapid overview is presented on how hypoxia originates in different pathologic conditions and how this leads to the inflammation.

\section{Hypoxia and Inflammation in Cancer}

Virchow first noted that inflammatory cells are present within tumors and that tumors frequently arise at sites of chronic inflammation. Today we know that in the site of a chronic inflammation a toxic concentration of free radicals may facilitate the tumorigenesis by favoring DNA mutation accumulation (transformation) [23]. Thereafter, transformed cells rapidly proliferate producing small $(400 \mu \mathrm{m}$ in diameter) tumors in the absence of neoangiogenesis and thus generating a hypoxic microenvironment. Hypoxia has two effects on tumor cells: 1-necrosis of cells in the inner region of the tumor, more distant from host tissue vessels. 2adaptation of cells to the hypoxic gradient within the tumor through the activation of HIF $1 \alpha$ and expression of many genes such as VEGF (which is important in tumor neoangiogenesis), Glutl and HKII (which explain the metabolic remodeling of malignant tumors) and RAGE, P2X7, Toll-like, etc. (alarmin receptors) (Fig. 1) [1, 7, 8, 11, 20, 24, 40-46]. Importantly, necrotic cells release alarmins (HMGB1, ATP/ADP, membrane debris, nucleic acids, etc.) that, by binding to their receptors, activate NFkB and hundreds of genes of the inflammatory reparative response (IRR) (Fig. 1) [45-60]. Therefore, transformed cells activate a gene response similar to that seen in activated leukocytes [44-46]. In solid human tumors (prostate ca [44], mammary ca $[8,43-46]$, glioblastoma [24] and thyroid papillary ca [61, $62])$ the upregulation of alarmin receptors and the increased expression of major IRR genes has been shown, comparing tumor with host normal LCMD tissue fractions, in the absence of leukocytes (CD45+ cells) [43-46, 61, 62].

Hypoxic treatment of various tumor cell lines reproduces a gene adaptation similar to that seen in solid tumors, leading to the malignant phenotype [44-46]. Inhibition of HIF $1 \alpha$ and/or NFkB in the same tumor cell lines prevents invasion and metastasis, suggesting a possibility to control tumor progression, by modulating inflammation through HIF $1 \alpha$ 
and NFkB inhibition. An early control of HIF1 $\alpha$ and/or NFkB activity could lead to a more efficient and less toxic therapeutic approach, not eradicating the tumor, but rather controlling its progression [36].

Presently, it is unclear if cancer stem cells can be the most susceptible target of these hypoxia-driven changes and if they can be blocked or controlled by modulating HIF $1 \alpha$ and NFkB activity.

\section{Hypoxia and Inflammation in Thrombosis: Role of Arterial Occlusion and Infarction}

Thrombus formation is a frequent cause of ischemic hypoxia due to the occlusion of an arterial vessel. Ischemia produces severe cell damage and necrosis in tissues due to shortage of oxygen and nutrients as it occurs in myocardial infarction and cerebral ictus $[63,64]$. Similarly to what we have described in tumors, necrotic cells release alarmins, while in surviving cells HIF $1 \alpha$ is activated, changing the cell phenotype with the expression of alarmin receptors and activation of NFkB [63, 65-67]. It is well known that a few hours after infarction, HMGB1 and other alarmins are released $[64,68]$ and myocardial tissue or cerebral tissue can be infiltrated by recruited and activated leukocytes, contributing to the amplification of inflammatory response, to salvage and repair of damaged tissue [64, 68, 69]. However, it is well known that a prolongation of this phase is harmful leading to a pathological remodeling of the myocardium $[63,65]$.

\section{Hypoxia and Inflammation in Obesity: Role of Adipocyte Hypertrophy}

Obesity is probably initiated by chronic overnutrition and decreased energy expenditure (sedentary lifestyle) [70]. At level of white adipose tissue (WAT) this imbalance leads to an accumulation of fat nutrients as lipid droplets in the cytoplasm of adipocytes which progressively undergo hypertrophy, leading to the increase of white fat mass or obesity. Inadequate metabolic homeostasis and insufficient vascular perfusion are responsible for cell stress, local hypoxia, HIF-dependent adaptation and necrosis of adipocytes that are more distant from vessels. Hypoxia progressively occurs as the ratio vessel/adipose tissue area decreases [70-72]. The activation of HIF $1 \alpha$ produces metabolic changes favoring insulin-resistance and type II diabetes, production of ROS, and expression of TLRs, NLRs, RAGE and P2X7 all activating NFkB and a nonleukocytic inflammatory response. The gene expression directed by NFkB includes cytokines, adipokines and chemokines, numerous classical inflammatory mediators and production of ROI and RNI. The latter two are responsible for adipocyte necrosis, while mediators activate resident leukocytes and recruits distant and circulating white cells, increasing the local inflammation firstly activated in adipocytes [73]. AT resident macrophages and lymphocytes may increase from less than $10 \%$ to more than $40 \%$ [73]. The involvement of distant organs (especially hepatocytes and skeletal muscle) creates a stable vicious metabolic circle maintaining local and systemic inflammation, aggravating insulin-resistance and metabolic dysfunctions, strongly contributing in this way to the pathogenesis of type II diabetes and metabolic syndrome [72, 74]. Adipocyte necrosis initially produced by ROI and RNI is relevant for IRR amplification and for AT fibrosis: necrotic adipocytes release alarmins which, acting on alarmin receptors of local adipocytes and resident leukocytes, activate and amplify local inflammation. Additionally IRR chronically stimulates repairing pathways, especially TGF- $\beta$ pathway, leading to AT fibrosis [70].

\section{Hypoxia and Inflammation in Diabetes Complications: Role of ECM and BM Thickness}

Inflammation contributes to the primary pathogenesis of diabetes (i.e. damage of the insulin-producing $\beta$-cells and metabolic abnormalities increasing insulin-resistance), but it is as much relevant for the pathogenesis of the devastating complications including diabetic nephropathy, diabetic cardiomyopathy, retinopathy, great vessel involvement, peripheral arm and legs microvasculopathy and cerebral vasculopathy with brain hypotrophy [75]. All of them develop in association with a peculiar microvasculopathy due to an accumulation of AGEs, consequent hypoxia and inflammatory response with tissue damage. In the individual patient the severity of diabetes is not necessarily associated with high levels of hyperglycemia and metabolic abnormalities, but rather with these complications occurring preferentially in a specific organ or tissue, probably depending on individual susceptibility to non-enzymatic glycation and hence to the local accumulation of AGEs $[74,76]$.

Due to diabetic hyperglycemia, proteins undergo heavy non-enzymatic glycation forming and accumulating AGEs. Slow turn-over, long-lasting proteins forming ECM and basement membranes may be particularly susceptible and relevant for the pathogenesis of microangiopathy, because they rapidly accumulate around the vessels, in the ECM and in basement membranes of tissues, thus increasing the distance between the lumen of vessels and the cells of tissue that need to be fed (nourished) with oxygen and nutrients by simple diffusion (Fig. 2). In this way a hypoxic microenvironment is generated activating HIF $1 \alpha$ and inflammatory response. In diabetes a substantial contribution to the activation of NFkB arise from RAGE signaling. RAGE, firstly identified for its binding to AGEs, is an alarmin receptor constitutively expressed by CD45+ cells (leukocytes) or induced by HIF1 $\alpha[45,46,77]$. The natural specific ligand of RAGE, under normal conditions, is the cytokine/alarmin HMGB1 having the highest binding affinity [13], but in diabetes a phenomenon of spill-over occurs due to high concentrations of AGEs that may saturate RAGE.

\section{Hypoxia and Inflammation in Abnormal Hypertrophy with Insufficient Neoangiogenesis}

Cell hypertrophy is an increase of cell volume due to abnormal synthesis of normal molecules and organelles, specific of a cell type. In physiologic myocardial hypertrophy $[78,79]$, such as that in trained athletes, sarcomere components, mitochondria and regulatory proteins harmonically increase leading to myocardiocyte volume increase with normal contractile function. Parallel vessels and stroma increased 
A

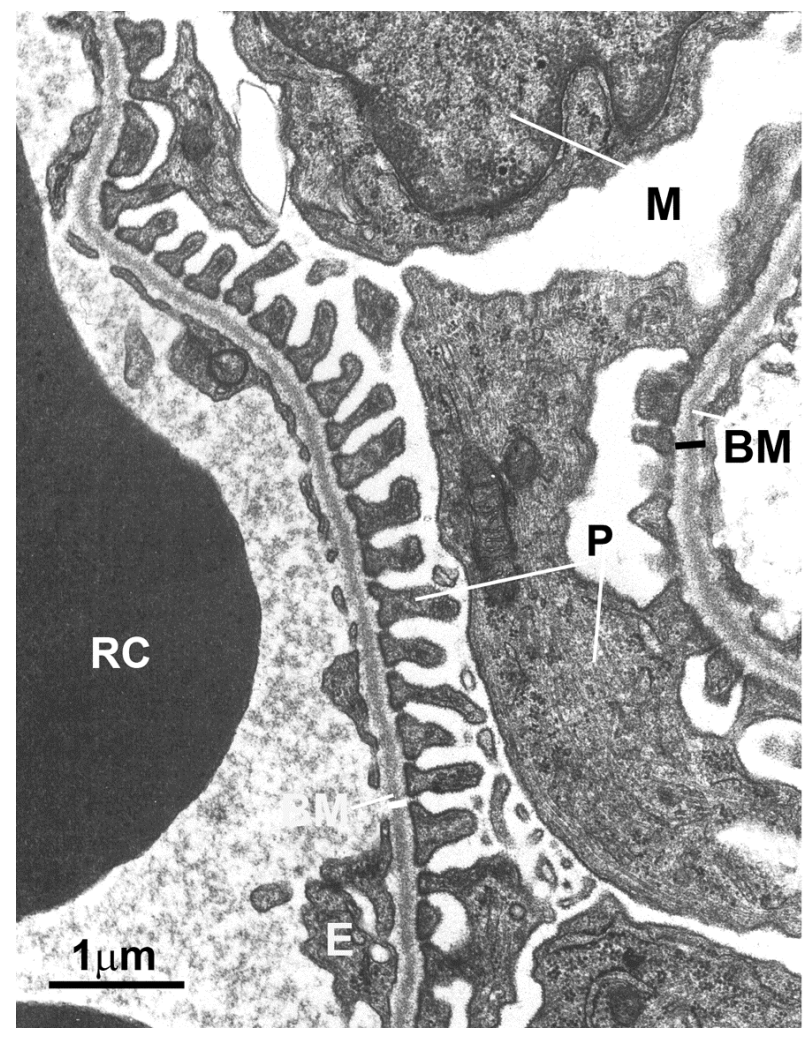

B

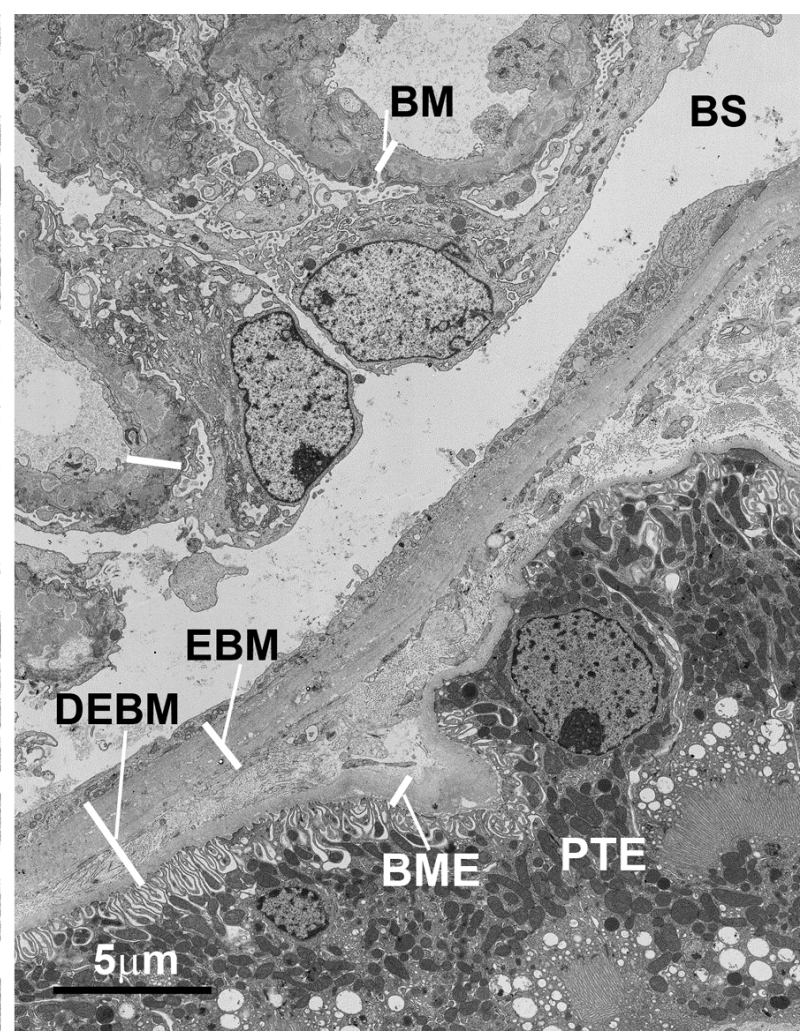

Fig. (2). Diabetic nephropathy: increased thickness of basement membranes. A - Detail of a normal glomerulus in the basement membrane $(\mathrm{BM})$ has an average thickness of $200-300 \mathrm{~nm}$. B - Detail of diabetic kidney basement membranes and extracellular matrix (ECM): there is an average of ten-fold increase as compared to the normal. Collagen and ECM components are also augmented. BM = basement membrane; $\mathrm{BME}=$ basement membrane of the epithelial cells; BS = Bowman's Space; DEBM = basement membrane of the capsular and tubular epithelium; $\mathrm{E}=$ endothelial cell; $\mathrm{P}=$ epithelial (podocyte) cell with foot processes; $\mathrm{M}=$ mesangial cell; $\mathrm{PTE}=$ proximal tubule epithelial cells; $\mathrm{RC}=$ red cell.

and remodeled for an optimal contractile performance [78]. Abnormal hypertrophy, such as that occurring in hypertension or in loss-of-function mutation of sarcomeric proteins, increase of sarcomeric components overcome the mitochondrial, vessel and stroma adaptations, with abnormal organization of contractile fibrils (sarcomeric disarray with abnormal direction of the contractile force) [79]. Also in this case the ratio vessel area/myocardiocyte area is sharply decreased giving rise to a hypoxic condition similar to that seen in obesity. In different types of hypertrophic cardiomyopathy an insufficient vasculature and an increase of leukocytes have been described [80]. In conclusion, in various conditions of abnormal cell hypertrophy, with relative decrease of vascular perfusion the pathway HIF $1 \alpha-$ NFkB may be activated primarily by hypoxia, suggesting a role in the long-term damage of the tissue, leading to functional insufficiency and fibrosis. It is unknown if targeting HIF-NFkB pathway may have beneficial effects in slowing or blocking the progression of these conditions.

\section{Hypoxia and Inflammation in Storage and Neuro- degenerative Disease: Role of False Hypertrophy}

False hypetrophy is a cell volume increase due to an abnormal accumulation of molecules and components that normally should be properly eliminated before an evident storage occurs. Adipocyte hypertrophy can be defined false hypertrophy, but a number of other diseases may show false hypertrophy with evident increase in cell volume, in parallel with accumulation of abnormal molecular components, depending on type of disease (Table 2) [71, 74, 81-90]. In storage diseases accumulation occurs in cytoplasm (glycogen) or in lysosomes (mucopolysaccarides, complex lipids and other molecules) and in several neurodegenerative diseases poliglutaminic proteins accumulate into the cytosol as monomeric forms or as polymeric fibrils (Huntington disease, Parkinson disease, etc.) [82-86, 91]. Abnormal proteins may be found as monomers, but more frequently as protease-resistant $\beta$-fibrils, both inside the cell (prion diseases) and/or in the extracellular space around the affected cells. In the Alzheimer disease $\beta$-fibrils originate from abnormal tau proteins and accumulate into the cytosol (tangles), but also originate from polymeryzation of secreted $\beta$-amyloid peptide, forming typical extracellular plaques [87]. In several other conditions, generally named $\beta$ fibrillosis, in which an excess of abnormal $\beta$-sheet rich protein is synthesized, $\beta$-fibrils may polymerize and accumulate in the intracellular and extracellular space.

All these conditions have in common the false cell hypertrophy which establish in the tissue a progressively insufficient perfusion, giving rise to a hypoxic 
Table 2. Examples of false hypertrophy in which tissues undergo hypoxia for vasculature insufficiency.

\begin{tabular}{|c|c|c|c|c|}
\hline Disease & Hypertrophy Pathogenesis & Vasculature Alteration & Hypoxic/inflammatory Features & References \\
\hline \hline Obesity & $\begin{array}{c}\text { Lipid droplet accumulation in } \\
\text { adipocytes }\end{array}$ & $\begin{array}{c}\text { Insufficient vascular bed in } \\
\text { white adipose tissue }\end{array}$ & $\begin{array}{c}\text { HIF1 } \alpha / \text { NFkB activation; mediator } \\
\text { and effector synthesis; increased } \\
\text { resident leukocytes; fibrosis. }\end{array}$ & [37, 41, 49] \\
\hline Lysosomal diseases & $\begin{array}{c}\text { Glycogen, complex lipid or } \\
\text { mucopolysaccaride accumulation } \\
\text { into lysosomes }\end{array}$ & $\begin{array}{c}\text { Insufficient vascular bed when } \\
\text { vessels are affected. Insufficient } \\
\text { vasculature in advanced diseases } \\
\text { with unaffected vessels }\end{array}$ & $\begin{array}{c}\text { Increased tissue leukocytes; necrosis; } \\
\text { fibrosis }\end{array}$ \\
\hline $\begin{array}{c}\text { Cytosolic storage } \\
\text { diseases }\end{array}$ & $\begin{array}{c}\text { Glycogen, cristal 52] } \\
\text { (cystine, cholesterol, uric acid), } \\
\text { fibril accumulation }\end{array}$ & $\begin{array}{c}\text { Insufficient vascular bed in } \\
\text { advanced diseases. }\end{array}$ & $\begin{array}{c}\text { Increased tissue resident leukocytes; } \\
\text { fibrosis }\end{array}$ \\
\hline $\begin{array}{c}\text { Neurodegenerative } \\
\text { diseases }\end{array}$ & $\begin{array}{c}\text { Neuronal hypertrophy for abnormal } \\
\text { polyglutaminic or fibrillar protein } \\
\text { accumulation into the cytosol }\end{array}$ & $\begin{array}{c}\text { Insufficient vascular bed only in } \\
\text { advanced disease. }\end{array}$ & $\begin{array}{c}\text { Increased tissue leukocytes, fibrosis } \\
\text { [51, 52, 54] }\end{array}$ \\
\hline $\begin{array}{c}\text { Amyloidosis or } \\
\beta \text {-fibrillosis }\end{array}$ & $\begin{array}{c}\text { Intracellular and/or extracellular } \\
\text { deposits of } \beta \text {-fibrils as polymers of } \\
\text { abnormal peptides }\end{array}$ & $\begin{array}{c}\text { Insufficient and compressed } \\
\text { vessels by amyloidosic mass }\end{array}$ & $\begin{array}{c}\text { Toll-like receptor activation; fibrosis } \\
{[54]}\end{array}$ \\
\hline
\end{tabular}

References are indicated and discussed in the text.

microenvironment and consequent activation of the HIF $1 \alpha-$ NFkB pathway, cell/tissue damage, chronic inflammation, repair and fibrosis. All these features have been described in the various phases of long-duration and slow progression of these diseases. For instance, we have evidences that in Fabry's disease accumulation of glycolipid bodies causes false hypertrophy in myocardiocytes leading to a hypertrophic heart and in perivascular fibroblast, in vascular smooth muscle cells and in endothelial cells producing an evident reduction or obliteration of the vascular lumen which further contributes to the hypoxia [83].

\section{Hypoxia and Inflammation in Chronic Inflammatory Diseases (Lung Injury, Inflammatory Bowel Diseases, Chronic Arthritis and Autoimmune Diseases)}

Primary chronic inflammation, such that occurring in COPD, in inflammatory bowel diseases, in chronic arthritis and autoimmune diseases all have in common a primary IRR with impaired resolution and tissue damage leading to fibrosis and hypoxia [92, 93]. In these conditions initial inflammation and ROI and RNI production are probably the early events of the disease. Afterwards, the progressive edema, damage and fibrosis are the determinants for the activation of HIF/NFkB pathway and the maintenance of the chronic inflammation leading to the final insufficiency [92, 93]. ROI and RNI are produced mainly by endogenous metabolism ( $80 \%$ of the oxygen is used by mitochondria) and by constitutive or inducible enzymes such NOS. Hypoxia and stimulation by GFs or cytokines contribute to activate free radical production, together with external factors such as radiations, UV, chemotherapy and activators of metabolism such as diet and physical activity (Fig. 3). Free radicals are highly reactive with all biological molecules and represent damaging agents for our cells. For this reason a number of highly redundant mechanisms and molecules have been selected by the evolution to control their intracellular harmful concentration [26]. Major ROS detoxifying mechanisms are represented in Fig. 3 and include cytosolic and mitochondrial SOD, Glutathione, peroxidases, redoxins and exogenous and dietary antioxidants. Intracellular bilirubin a byproduct of the hemeoxygenase 1 is an efficient scavenger in that 1 mole of bilirubin can inactivate 2000 moles of radicals [94].

At physiological concentrations intracellular radicals are major modulators of several master transcription factors (Fig. 4) such as NFkB, AP-1, STAT3, Nrf2, HIF1 $\alpha$ and others all involved in the hypoxia-related proinflammatory pathway involving HIF/NFkB [95-98].

In summary such chronic inflammatory diseases are triggered and maintained by chronic inflammation with the aggravation of an hypoxic condition activating the HIF/NFkB pathway.

\section{Hypoxia and Inflammation in Ageing and Age-related Diseases}

Aged tissues may become chronically relatively hypoxic due to ageing of vasculature, especially microvessels, and to the increase of fibrotic and abnormal components of stromal over parenchymal part.

Ageing is considered a progressive degradation of body functions over time, caused by a discrepancy between tissue/cell damage and the homeostatic ability to repair cells and restore the lost function. This results in the accumulation of molecular damage especially on DNA and proteins with the involvement of a number of important functions. For instance in ageing there is an increase in intracellular oxidative stress due from one side to the progressive decrease of the intracellular ROS scavenging, from the other side to an abnormal proinflammatory age-related chronic 


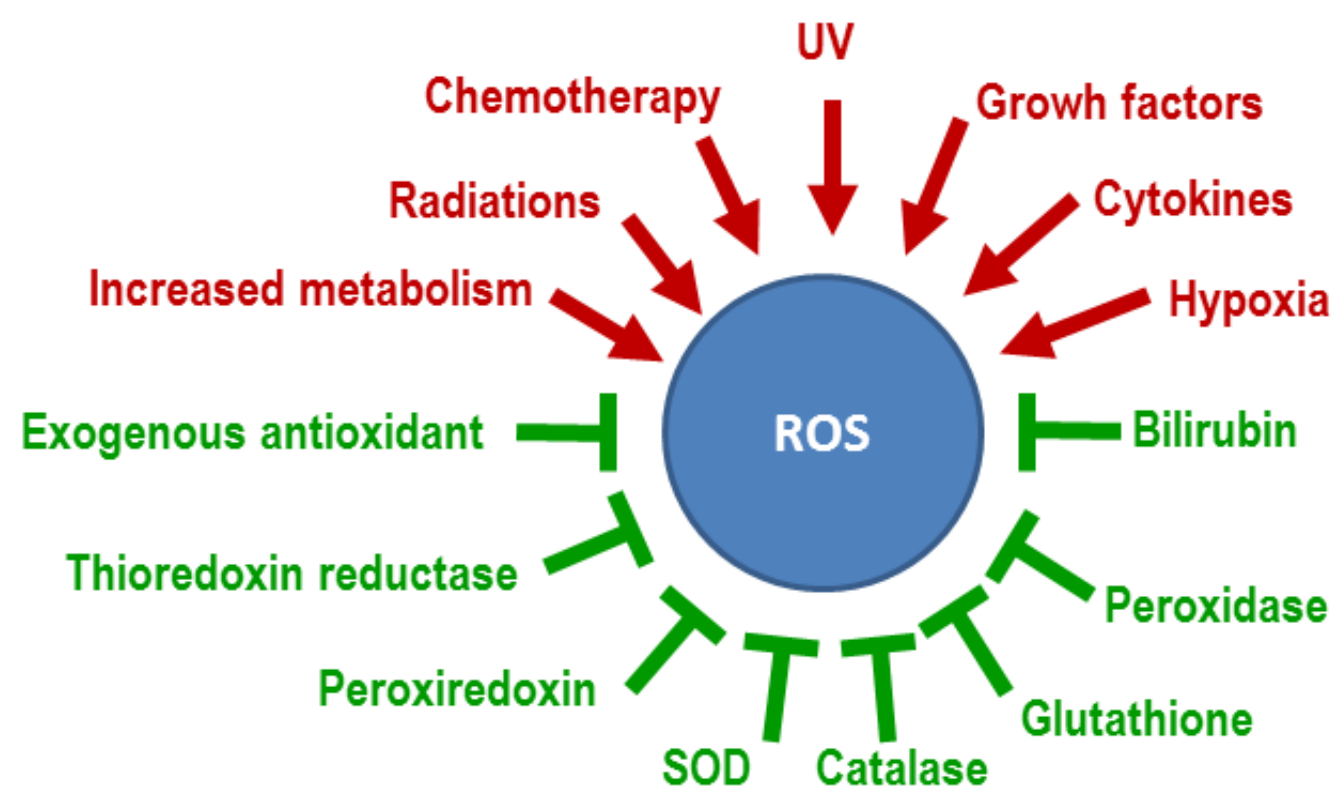

Fig. (3). Generation of ROS by endogenous or exogenous stimuli (red) and their major detoxifying mechanisms (green). [Modified from 26].

systemic state $[99,100]$. The last one is produced by several synergic factors including a degraded control of IRR, the insurgence of new antigens (as abnormal/mutated proteins) causing various autoimmune diseases, an increase on AGEs which activate the alarmin receptor RAGE, and a systemic sublethal damage releasing HMGB1 and other endogenous alarmins. Due to the chronic and progressive accumulation of tissue damage, inefficient repairing mechanisms (the stem cell compartment is decreased in function and number of cells) privilege the formation of fibrotic healing with an accumulation of fibrous tissue in aged parenchymas. This general tissue degradation together with vasculature ageing may lead to a chronic hypoxic/proinflammatory condition similar to that seen before [101].

\section{TARGETING HIF AND INFLAMMATION PATHWAYS AND MOLECULES}

In this review the pathway HIF-NFkB has been indicated as the highway of signaling bridging hypoxia with inflammation leading to the associated damage, consequently, it appears relatively simple, in principle, to target the molecular component to modify the outcome of all the above mentioned diseases (Fig. 4). However, the problem is much more complex and challenging for many reasons: first, there are many secondary alternative pathways that can be activated if the main one is inhibited; second, we still do not know what is the toxicity and the unwanted side-effects of this therapeutic strategy; finally, some of these agents (especially inhibitors of HIF and NFkB) are natural products or off-label drugs which need to be endorsed on specific clinical trials for these diseases.

\section{Targeting HIF}

HIF $1 \alpha$ has become the target of an increasing number of inhibitors developed with the aim to block or reduce tumor growth and progression $[102,103]$ and that could also be useful in other hypoxia-related pathologies described above. The different mechanisms that can be exploited to achieve a significant HIF inhibition have been extensively detailed by us [36]. Here we will review the major molecules inhibiting HIF in vitro and/or in vivo.

HIF activity can be inhibited by preventing protein accumulation as in the case of the PI3 kinase inhibitor wortmannin or the mTOR inhibitor rapamycin [104, 105]. Similarly, HIF protein expression is inhibited by digoxin a cardiac glycoside [102] and by 2 methoxyestradiol (2ME2), a microtubule targeting agent that has been shown to inhibit HIF cytosol to nuclear shuttling [106]. HIF can also be inhibited by altering its post-translational modifications such as acetylation/deacetylation by using modulators of class II and class III, histone deacetylases (HDAC), the latter also known as sirtuins [107, 108]. Molecules falling in this category are trichostatin and resveratrol that modulate the activity of class II and class III HDAC, respectively. However, in this case, while class II HDAC inhibition determines an increased degradation of HIF by increasing its ubiquitination, the mechanism of action of sirtuins activators is more complex and less known. In fact, deacetylation of HIF by sirtuins and in particular SIRT1 and SIRT6 has been shown to deacetylate HIF thereby decreasing its transcriptional activity [107]. In addition sirtuins modulation is complicated by the fact that they also have and antioxidative function with reduction of reactive oxygen species (ROS) production. Since HIF is stabilized by ROS accumulation, sirtuins inhibition of HIF is also achieved by preventing ROS accumulation in the cell $[109,110]$. A large number of natural products have been shown to inhibit HIF by different mechanisms such as proteasomal degradation as in the case of curcumin [111], moracin $O$ and $P$ [112]; increased HIF degradation such as in the case of resveratrol $[113,114]$ and Sibiriquinone A [115]. HIF $1 \alpha$ can be inhibited by preventing its dimerization to HIF $1 \beta$ as in the case of the antibacterial agent acriflavine [116], by inhibiting 


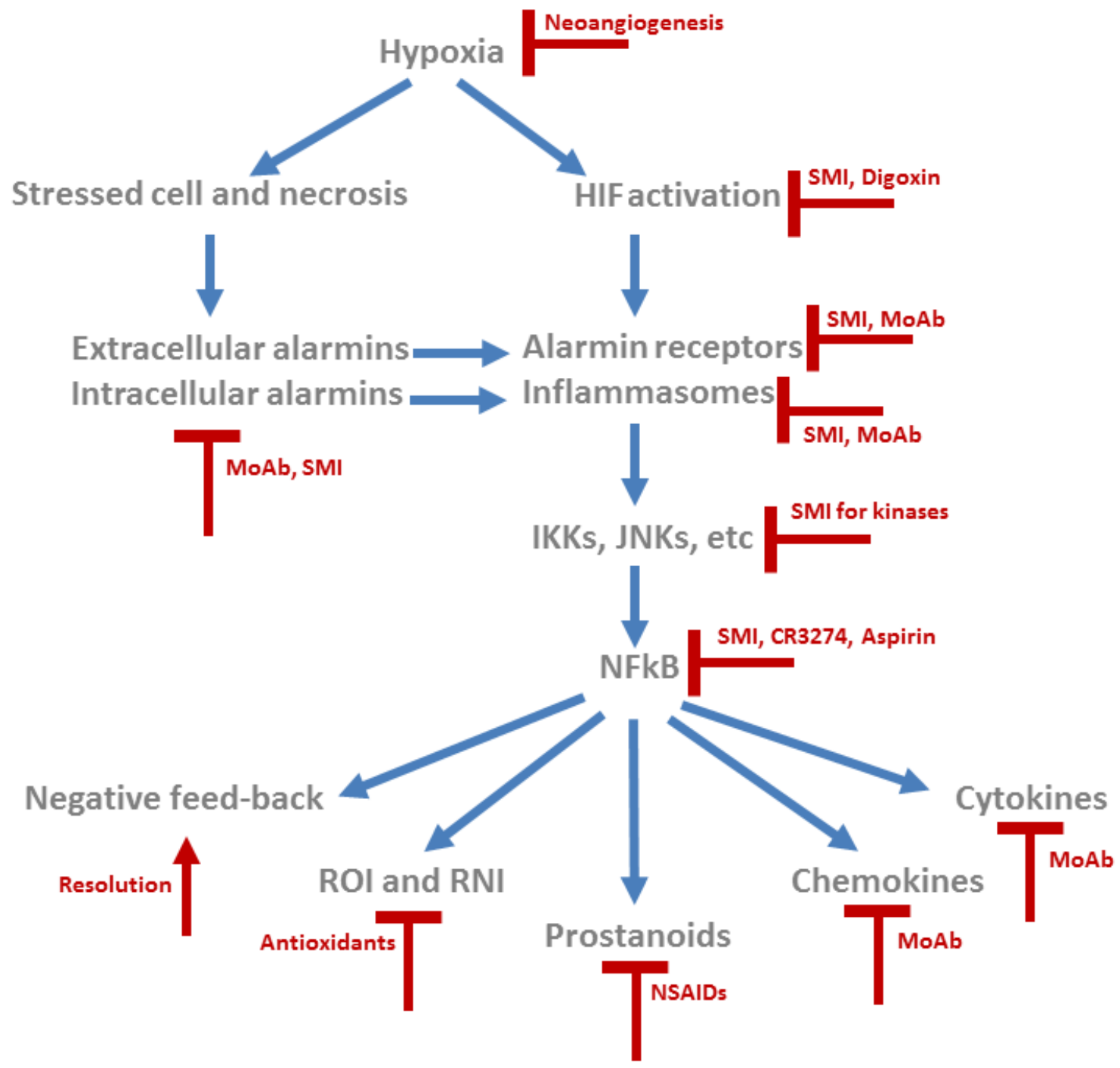

Fig. (4). Targeting the HIF/NFkB pathway. SMI = small molecule inhibitors, means "specific" compunds that have shown a "specific" or "quasi-specific" inhibitory activity on a single member of the HIF/NFkB pathway. MoAb = monoclonal antibodies: they have been produced against a specific protein, showing a inhibitory effect on their biological action. The lists of these compounds and MoAbs and their relative references are extremely long and are out of the scope of this review. NSAIDs = non-steroidal antinflammatory drugs [28].

its DNA binding as in the presence of doxorubicin or daunorubicin [117], or, finally, by preventing HIF1 $\alpha$ binding to its coactivator $\mathrm{p} 300$ as in the case of chetomin or bortezomib [118, 119].

\section{Targeting Alarmin Receptors}

Alarmin receptors are localized on the cell surface (plasmamembrane) or on intracellular membranes (endosomes, phagosomes) and recognize repeated structures present in exogenous (microbes) or endogenous (host) molecules [13, 120]. Classic members of the alarmin receptors are: receptor for advanced glycation endproducts (RAGE) and toll like receptors (TLRs). The main role of alarmin receptor is to recognize a molecular pattern associated either to the presence of a pathogen or to necrotic cells. The binding of alarmin receptors to their ligand results in the activation of an inflammatory response through the formation of inflammasome and engagement of NFkB [36, 61]. The observation that alarmin receptors are capable to initiate and propagate inflammation has made them attractive target for the treatment of many inflammatory diseases.

In the case of RAGE, strategies are focused on inhibiting its interaction with advanced glycation endproducts (AGEs), on blocking RAGE or on inhibiting its signaling [121]. In the first strategy, inhibition of AGE accumulation by molecules such as aminoguanidine (Pimagedine ${ }^{\mathbb{R}}$ ), Pyridoxamine, a vitamin B complex, lysozyme and other AGE blocking agents result in amelioration of vascular functions and reduction of other complications observed in diabetic patients, in prevention of neuropathy and retinopathy in diabetic animal models and in reducing the severity of diabetic retinopathy [122].

Blockage of RAGE has been successfully obtained by using the natural presence of a soluble form of RAGE (sRAGE). In fact, sRAGE synthesis is decreased under pathologic conditions such as coronary artery disease, 
hypertension, metabolic syndrome, arthritis and Alzheimer's disease. Therefore, exogenous administration of sRAGE or of drugs such as angiotensin converting enzyme treatment or pioglitazone has shown beneficial effects in diabetic patients $[121,123]$.

RAGE signaling blockage is a promising therapeutic target that has been observed in drugs such as metformin, an anti-hyperglycemic agent, that reduces protein glycation and also prevents NFkB activation by RAGE [122]. Other inhibitors of RAGE-axis are the dipeptidyl peptidase 4 (DPP 4) inhibitors Sitagliptin, Alogliptin, and Vildagliptin that preserves the pancreatic $\beta$-cell function [124]. Finally, additional agents in clinical use with reported anti-RAGE effects are angiotensin 1 receptor blocker (Relmisartan), a dihydropyridine based calcium antagonist (Nifedipine) and prostacyclin analog (Beraprost sodium) [121].

In the case of TLRs most of the studies demonstrating their role in human pathologies have been done in vitro or in animal models. In fact few molecules are approved for human use, one of this being imiquimod that has been approved for the treatment of genital warts, actinic keratosis and nonmelanoma skin cancers [125]. Its mechanism of action proceeds through activation of TLR7 and 8 with modulation of the immune response. However, the possibility to prevent or reduce inflammation-associated pathologies is linked to a better understanding of TLRs function that requires more research. In fact, mice lacking TLRs develop inflammatory diseases, such as arthritis, multiple sclerosis and inflammatory bowel disease.

On the other hand, TLR activation occurs early in the cascade of events that give rise to inflammation. Therefore, there might be an advantage in blocking them as they might give rise to chronic inflammation. Importantly, TLRs also detect products released from inflamed tissue, an event that feedback, on TLRs, leading to further activation. Breaking such a, positive feedback loop may be a highly effective strategy, to limit inflammation. From these considerations it is clear that both agonists and inhibitors of TLRs have been developed to prevent diverse human pathologies as extensively reviewed by Hennessy, 2010 [126].

TLRs agonists have been studied to prevent cancer, viral and bacterial infections as well as for autoimmunity. In particular, single stranded RNA-based TLR7 and TLR8 agonists have been used for the treatment of cancer and infectious diseases; $\mathrm{CpG}$-based oligonucleotides that mimic unmethylated bacterial DNA are also being evaluated as potential anticancer drugs [127, 128]. Immune modulatory oligo nucleotides (IMOs) such as IMO-2055 have anticancer activity in a mouse model when used as a monotherapy and this activity was amplified when it was used in combination with chemotherapeutic agents [128].

Noncoding DNA called MGN-1703 and MGN-1706 are double stem-loop immunomodulating adjuvants developed as anticancer TLR9 agonists. A purified, water soluble diphosphorylated and triacetylated lipid-A derived from $E$. coli known as OM-174 acts as a TLR4 agonist. It reduces tumour growth, increases IFN $\gamma$ production and prolongs the survival of mice $[129,130]$. The TLR2 agonist SMP-105 that consists of cell-wall components, from Mycobacterium bovis (strain BCG/Tokyo), is approved for the treatment of bladder cancer. In mice, SMP-105 activates NFkB in a TLR2-dependent and TLR4-independent manner. Upon administration of the compound, TLR2 knockout mice showed impairment of TNF- $\alpha$ and IL-6 production as well as reduced tumor growth [131]. Resiquimod (R-848) is currently being evaluated for treating hepatitis $\mathrm{C}$ and other viral infections [132]. A small-molecule TLR7 agonist, ANA773, is under investigation for the potential treatment of hepatitis C infection and cancer [133]. Finally, vTX-1463 reduced allergic responses through the suppression of a Th2mediated allergic response. When administered intranasally, it resulted in a decrease in the number of eosinophils and less congestion [126].

Extensive research has been developed to search for TLRs antagonist as novel therapeutics. Derivatives and small-molecule analogues of antimalaria drugs chloroquine and quinacrine act as a TLR9 antagonist suppress activation of an immune response [134]. The quinazoline derivative CPG-52364 is an anti-inflammatory TLR antagonist which specifically inhibits TLR7, TLR8 and TLR9 and inhibits disease progression of autoimmune diseases in animal models [135]. TLR4 antagonistic antibodies are being developed to block immune signaling in diseases associated with an excessive immune response. The most advanced is NI-0101, which interferes with the dimerization of TLR4 [136]. Similarly, 1A6 is an antibody that recognizes TLR4MD-2 and it delayed the development of colitis and reduced the inflammatory response in a mouse model. However, when the antibody was administered during the recovery stage of the disease it impaired mucosal healing [136].

\section{Targeting Inflammasome}

Pharmacological manipulation of inflammasome activity is under extensive investigation due to the central role of inflammasome components such as NLRs to mediate the response to PAMPS and DAMPS [137]. Currently, the best treatments for inflammasome disorders aim to target the main product of inflammasome activity, IL-1 $\beta$. Inhibition of IL-1 may be achieved at different levels. Some substances such as monoclonal antibodies target IL-1 molecule directly (canakinumab, rilonacept, gevokizumab) while others are antagonists of IL-1 receptor (anakinra) [138, 139]. Other strategies for treating IL-1 related disease rely on antagonists of $\mathrm{P} 2 \mathrm{X} 7$ receptor to treat LES and on caspase-1 inhibitors [140]. Small-molecule inhibitors of NLRP3 such as Glyburide are used in the treatment of T2D, where it inhibits IL-1 $\beta$ production by acting upstream of NLRP3. Parthenolide is a sesquiterpene lactone that has multiple anti-inflammatory properties. Separate to its effects on NFkB activation, parthenolide has now also been shown to inhibit caspase-1 and NLRP3 [141].

Bay11-7082 is another NFkB inhibitor that was also found to specifically inhibit NLRP3 by preventing the ATPase activity of NLRP3 [141]. Currently, available inhibitors of inflammasome function have either not been clinically successful or have multiple targets. Therefore, the development of small molecule inhibitors that directly target the NLRP3 inflammasome could provide a more efficient 
therapy for treating IL-1 $\beta$ and inflammasome-related diseases.

In conclusion, our understanding of the precise mechanism of the NLRP3 inflammasome is still scattered. However, given the importance of NLRP3 for inflammatory diseases, more information on its modulation will help our understanding of NLRP3 in disease and its potential therapeutic manipulation.

\section{Targeting NFkB and NFkB-dependent Genes}

NFkB has a central role in the cellular response to inflammation: this transcription factor regulates the expression of hundreds of genes that, in turn, control a large number of intracellular pathways. As in the case of HIF, the importance of $\mathrm{NFkB}$ inhibition for the prevention or reduction of many human pathologies has been extensively reviewed by us [36]. Importantly, many NFkB inhibitors are off-label drugs already used in medicine or natural compounds.

Generally, inhibition of $\mathrm{NFkB}$ can be obtained by exploiting the diverse mechanisms controlling its stability due for example to post translational modifications or by preventing its nuclear translocation and accumulation.

In particular parthenolide, curcumin, aspirin and ibuprofen can inhibit NFkB by interacting and blocking IKK kinase that phosphorylates and activates NFkB [142-144]. Other IKK inhibitors are natural compounds such as Bcarboline derived from plants and anti-inflammatory drugs such as sulindac and sulfasalazine [145]. Finally, NFkB can be inhibited by using phosphatases activators such as cytosine arabinoside [146].

Inhibition of proteosomal degradation of $\mathrm{IkB}$, a regulatory protein that binds to $\mathrm{NFkB}$ and retains it in the cytoplasm, results in the inhibition of $\mathrm{NFkB}$ activity. Bortezomib is the most studied since has shown some important results in reducing tumor growth when used as a adjuvant to standard chemotherapy [147]. These results have lead to the synthesis of new proteasome inhibitors such as carfilzomib and salinosporamide that can be used at nanomolar ranges with lower toxicity [148, 149].

Acetylation/deacetylation of NFkB is another posttranslational modification that can be influenced to regulate NFkB activity. In particular, since acetylation activates NFkB, inhibitors of acetyl transferases such as p300 or activators of deacetylases such as sirtuins as been shown to prevent NFkB activation and the following inflammation, tumor growth, etc. [149].

Finally, NFkB activity can be regulated by preventing its nuclear shuttling and accumulation. Very few substances can inhibit NFkB nuclear translocation and more studies are needed. However, dehydroxymethylepoxyquinomicin (DHMEQ) derived from an antibiotic has shown antiinflammatory and anti-tumoral activity by preventing nuclear accumulation of NFkB [150].

\section{CONCLUSIONS}

Hypoxia and inflammation are strictly and sequentially related at the molecular, cellular, and clinical levels. They have a crucial role in pathogenesis of a number of severe and widespread chronic diseases which in Western countries are increasing with the life expectancy. Pathways including oxygen sensing mechanisms, HIF-dependent genes, IRR activation and NFkB-dependent genes are potential therapeutic targets for the treatment of devastating diseases such as cancer, cardiovascular diseases, diabetes, obesity, neurodegenerative diseases and a number of other chronic invalidating inflammatory diseases.

However, such approaches should be clinically tested in all other patients in which hypoxia has been demonstrated to activate chronic inflammation, such as acute lung injury, myocardial ischemia and inflammatory intestinal disease. Finally, targeting hypoxia-dependent signaling pathways could also help attenuate organ failure due to ischemia in patients undergoing major surgery or alleviate hypoxiadriven graft inflammation after solid-organ transplantation.

\section{CONFLICT OF INTEREST}

The author(s) confirm that this article content has no conflict of interest.

\section{ACKNOWLEDGEMENTS}

This work was supported by RF-2011-02349126.

\section{LIST OF ABBREVIATIONS}

\begin{tabular}{|c|c|c|}
\hline AGEs & $=$ & advanced glycation end-products \\
\hline AP1 & $=$ & Activating protein 1 \\
\hline AT & $=$ & Adipose tissue \\
\hline COPD & $=$ & Chronic Obstructive Pulmonary Disease \\
\hline DAMPS & $=$ & Damage-Associated Molecular Patterns \\
\hline HIF & $=$ & Hypoxia inducible factor \\
\hline HMGB1 & $=$ & high mobility group box 1 \\
\hline JAK & $=$ & Janus kinase \\
\hline LCMD & $=$ & Laser capture microdissection \\
\hline NLR & $=$ & NOD-like receptors \\
\hline NFkB & $=$ & Nuclear factor \\
\hline PAMPs & $=$ & Pathogen-Associated Molecular Patterns \\
\hline $\mathrm{P} 2 \mathrm{X} 7$ & $=$ & Purinergic receptor $2 \mathrm{X} 7$ \\
\hline RAGE & $=$ & $\begin{array}{l}\text { receptor for advanced glycation end } \\
\text { products }\end{array}$ \\
\hline ROI & $=$ & Reactive Oxygen Intermediates \\
\hline RNI & $=$ & Reactive Nitrogen Intermediates \\
\hline SOCS & $=$ & suppressor of cytokine signaling \\
\hline STAT & $=$ & $\begin{array}{l}\text { Signal transducers and activators of } \\
\text { transcription }\end{array}$ \\
\hline TERT & $=$ & Telomerase reverse transcriptase \\
\hline $\mathrm{TF}$ & $=$ & transcription factor \\
\hline
\end{tabular}


TD2 $=\quad$ type 2 diabetes

VEGF $\quad=\quad$ vascular endothelial growth factor

\section{REFERENCES}

[1] Eltzschig, H.K.and Carmeliet, P. (2011) Hypoxia and inflammation. $N$ Engl J Med., 364, 656-65.

[2] Schanne, F.A.; Kane, A.B.; Young, E.E. and Farber, J.L. (1979) Calcium dependence of toxic cell death: a final common pathway. Science, 206, 700-2.

[3] Russo, M.A.; Cittadini, A.; Dani, A.M.; Inesi, G. and Terranova, T. (1981) An ultrastructural study of calcium induced degenerative changes in dissociated heart cells. $J \mathrm{Mol} \mathrm{Cell} \mathrm{Cardiol,} \mathrm{13,} \mathrm{265-79.}$

[4] Russo, M.A.; Kane, A.B. and Farber, J.L. (1982) Ultrastruct pathology of phalloidin-intoxicated hepatocytes in the presence and absence of extracellular calcium. Am J Pathol, 109, 133-44.

[5] Smith, M.A. and Schnellmann, R.G. (2012) Calpains, mitochondria, and apoptosis. Cardiovasc Res, 96, 32-7.

[6] Nagamalleswari, E.; Vasu, K. and Nagaraja, V. (2012) $\mathrm{Ca}(2+)$ binding to the ExDxD motif regulates the DNA cleavage specificity of a promiscuous endonuclease. Biochemistry, 51, 893949.

[7] Semenza, G.L. (2014) Oxygen sensing, hypoxia-inducible factors, and disease pathophysiology. Annu Rev Pathol., 9, 47-71.

[8] Tafani, M.; Schito, L.; Pellegrini, L.; Villanova, L.; Marfe, G.; Anwar, T.; Rosa, R.; Indelicato, M.; Fini, M.; Pucci, B. and Russo, M.A. (2011) Hypoxia-increased RAGE and P2X7R expression regulates tumor cell invasion through phosphorylation of Erk1/2 and Akt and nuclear translocation of NF-\{kappa\}B. Carcinogenesis, 32, 1167-75

[9] Sandholm, J.; Tuomela, J.; Kauppila, J.H.; Harris, K.W.; Graves, D. and Selander, K.S. (2014) Hypoxia regulates Toll-like receptor9 expression and invasive function in human brain cancer cells in vitro. OncolLett., 8, 266-274.

[10] Jones, H.D.; Crother, T.R.; Gonzalez-Villalobos, R.A.; Jupelli, M.; Chen, S.; Dagvadorj, J.; Arditi, M. and Shimada, K. (2014) The NLRP3 inflammasome is required for the development of hypoxemia in LPS/mechanical ventilation acute lung injury. Am $J$ Respir Cell Mol Biol., 50, 270-80.

[11] Tafani, M.; Perrone, G.A.; Pucci, B.; Russo, A.; Bizzarri, M.; Mechanick, J.I.; Carpi, A. and Russo, M.A. (2014) Reprogramming cancer cells in endocrine-related tumors: open issues. Curr Med Chem., 21, 1146-51.

[12] Strowig, T.; Henao-Mejia, J.; Elinav, E. and Flavell, R. (2012) Inflammasomes in health and disease. Nature, 481, 278-86.

[13] Bianchi, M.E. (2007) DAMPs, PAMPs and alarmins: all we need to know about danger. $J$ Leukoc Biol., 81, 1-5.

[14] Iwasaki, A. and Medzhitov, R. (2004). Toll-like receptors control of the adaptative immunity response. Nat Immunol., 5:987-995.

[15] Marshak-Rothstein, A. (2006) Toll-like receptors in systemic autoimmune disease Nat Rev Immunol, 6, 823-835.

[16] Fritz, J.H.; Ferrero, R.L.; Philpott, D.J. and Girardin, S.E. (2006) NOD-like proteins in immunity, inflammation and diseases Nature Immunol, 7, 1250-7.

[17] Yazdi, A.S.; Guarda, G.; Riteau, N.; Drexler, S.K.; Tardivel, A.; Couillin, I. and Tschopp, J. (2010) Nanoparticles activate the NLR pyrin domain containing 3 (Nlrp3) inflammasome and cause pulmonary inflammation through release of IL-1 $\alpha$ and IL-1 $\beta$. Proc Natl Acad Sci U S A., 107, 19449-54.

[18] Hillegass, J.M.; Miller, J.M.; MacPherson, M.B.; Westbom, C.M.; Sayan, M.; Thompson, J.K.; Macura, S.L.; Perkins, T.N.; Beuschel, S.L.; Alexeeva, V.; Pass, H.I.; Steele, C.; Mossman, B.T. and Shukla, A. (2013) Asbestos and erionite prime and activate the NLRP3 inflammasome that stimulates autocrine cytokine release in human mesothelial cells. Part Fibre Toxicol., 10, 39

[19] Robbins, G.R.; Wen, H. and Ting, J.P. (2014) Inflammasomes and metabolic disorders: old genes in modern diseases. Mol Cell, 54, 297-308.

[20] Kono, H. and Rock, K.L. (2008) How dying cells alert the immune system to danger. Nat Rev Immunol, $8,279-289$

[21] Burnstock, G. and Di Virgilio, F. (2013) Purinergic signalling and cancer. Purin Signal, 9, 491-540.

[22] Huynh, M.L.; Fadok, V.A. and Henson, P.M. (2002) Phosphatidylserine-dependent ingestion of apoptotic cells promotes
TGF- $\beta 1$ secretion and the resolution of inflammation. J. Clin. Invest., 109, 41-50.

[23] Grivennikov, S.I.; Greten, F.R. and Karin, M. (2010) Immunity, inflammation, and cancer. Cell, 140, 883-99.

[24] Tafani, M.; Di Vito, M.; Frati, A.; Pellegrini, L.; De Santis, E.; Sette, G.; Eramo, A.; Sale, P.; Mari, E.; Santoro, A.; Raco, A.; Salvati, M.; De Maria, R. and Russo, M.A. (2011) Pro-inflammatory gene expression in solid glioblastoma microenvironment and in hypoxic stem cells from human glioblastoma. J Neuroinflammation, 8, 32 .

[25] Ryan, B.J.; Nissim, A. and Winyard, P.G. (2014) Oxidative posttranslational modifications and their involvement in the pathogenesis of autoimmune diseases. Redox Biol, 2, 715-724.

[26] Reuter, S.; Gupta, S.C.; Chaturvedi, M.M. and Aggarwal, B.B. (2010) Oxidative stress, inflammation, and cancer: how are they linked? Free RadicBiol Med, 49, 1603-16.

[27] Martinon, F.; Burns, K. and Tschopp, J. (2002) The inflammasome: a molecular platform triggering activation of inflammatory caspases and processing of pro IL-beta. Mol Cell, 10, 417-26.

[28] Tabas, I. and Glass, C.K. (2013) Anti-inflammatory therapy in chronic disease: challenges and opportunities. Science, 339, 166-72. Rastrick, J. and Birrell, M. (2014) The role of the inflammasome in fibrotic respiratory diseases. Minerva Med, 105, 9-23.

[30] Walsh, J.G.; Muruve, D.A. and Power, C. (2014) Inflammasomes in the CNS. Nat Rev Neurosci, 15, 84-97.

[31] D'Elia, R.V.; Harrison, K.; Oyston, P.C.; Lukaszewski, R.A. and Clark, G.C. (2013) Targeting the "cytokine storm" for therapeutic benefit. Clin Vaccine Immunol, 20, 319-27.

[32] Mangge, H.; Becker, K.; Fuchs, D. and Gostner, J.M. (2014) Antioxidants, inflammation and cardiovascular disease. World $J$ Cardiol, 6, 462-77.

[33] Asghar, M.N.; Emani, R.; Alam, C.; Helenius, T.O.; Grönroos, T.J.; Sareila, O.; Din, MU.; Holmdahl, R.; Hänninen, A. and Toivola, D.M. (2014) In vivo imaging of reactive oxygen and nitrogen species in murine colitis. Inflamm Bowel Dis, 20, 1435-47.

[34] Vallabhapurapu, S. and Karin, M. (2009) Regulation and function of NF-kappaB transcription factors in the immune system. Annu Rev Immunol; 27, 693-733

[35] Napetschnig, J. and Wu, H. (2013) Molecular basis of NF-кB signaling. Аnпи Rev Biophys, 42, 443-68.

[36] Tafani, M.; Pucci, B.; Russo, A.; Schito, L.; Pellegrini, L.; Perrone, G.A.; Villanova, L.; Salvatori, L.; Ravenna, L.; Petrangeli, E. and Russo, M.A. (2013) Modulators of HIF1 $\alpha$ and NFkB in Cancer Treatment: Is it a Rational Approach for Controlling Malignant Progression? Front Pharmacol, 4, 13.

[37] Ahmed, T.J., Kaneva, M.K., Pitzalis, C., Cooper, D. and Perretti, M. (2014) Resolution of inflammation: examples of peptidergic players and pathways. Drug Discov Today, May 29. pii: S13596446(14)00227-X. doi: 10.1016/j.drudis.2014.05.020.

[38] Pruessmeyer, J.; Hess, F.M.; Alert, H.; Groth, E.; Pasqualon, T.; Schwarz, N.; Nyamoya, S.; Kollert, J.; van der Vorst, E.; Donners, M.; Martin, C.; Uhlig, S.; Saftig, P.; Dreymueller, D. and Ludwig, A. (2014) Leukocytes require ADAM10 but not ADAM17 for their migration and inflammatory recruitment into the alveolar space. Blood, 123, 4077-88.

[39] De Girolamo, L.; Stanco, D.; Salvatori, L.; Coroniti, G.; Arrigoni, E.; Silecchia, G.; Russo, M.A.; Niada, S.; Petrangeli, E. and Brini, A.T. (2013) Stemness and osteogenic and adipogenic potential are differently impaired in subcutaneous and visceral adipose derived stem cells (ASCs) isolated from obese donors. Int J Immunopathol Pharmacol, 26, 11-21.

[40] Fer, N. and Melillo, G. (2011) The HIF1 $\alpha$-cMyc pathway and tumorigenesis: evading the apoptotic gatekeeper. Cell Cycle, 10, 3228.

[41] Zhu, P.; Ning, Y.; Yao, L; Chen, M. and Xu, C. (2010) The proliferation, apoptosis, invasion of endothelial-like epithelial ovarian cancer cells induced by hypoxia. J. Exp. Clin. Cancer Res., 29, 124.

[42] Franovic, A.; Holterman, C.E.; Payette, J. and Lee, S. (2009) Human cancers converge at the HIF-2 oncogenic axis. Proc Natl Acad Sci U S A., 106, 21306-21311.

[43] Schito, L.; Rey, S.; Tafani, M.; Zhang, H.; Wong, C.C.; Russo, A.; Russo, M.A. and Semenza, G.L. (2012) Hypoxia-inducible factor 1-dependent expression of platelet-derived growth factor $B$ promotes lymphatic metastasis of hypoxic breast cancer cells. Proc Natl Acad Sci U S A, 109, E2707-16.

[44] Ravenna, L.; Sale, P.; Di Vito, M.; Russo, A.; Salvatori, L.; Tafani, M.; Mari, E.; Sentinelli, S.; Petrangeli, E.; Gallucci, M.; Di 
Silverio, F. and Russo, M.A. (2009) Up-regulation of the inflammatory-reparative phenotype in human prostate carcinoma. Prostate, 69, 1245-55.

[45] Tafani, M.; Schito, L.; Pellegrini, L.; Villanova, L.; Marfe, G.; Anwar, T.; Rosa, R.; Indelicato, M.; Fini, M.; Pucci, B. and Russo, M.A. (2011) Hypoxia-increased RAGE and P2X7R expression regulates tumor cell invasion through phosphorylation of Erk1/2 and Akt and nuclear translocation of NF-\{kappa\}B. Carcinogenesis, 32, 1167-75.

[46] Tafani, M.; Russo, A.; Di Vito, M.; Sale, P.; Pellegrini, L.; Schito, L.; Gentileschi, S.; Bracaglia, R.; Marandino, F.; Garaci, E. and Russo, M.A. (2010) Up-regulation of pro-inflammatory genes as adaptation to hypoxia in MCF-7 cells and in human mammary invasive carcinoma microenvironment. Cancer Sci, 101, 1014-23.

[47] Desgrosellier, J.S. and Cheresh, D.A. (2010) Integrins in cancer: biological implications and therapeutic opportunities. Nat Rev Cancer., 10, 9-22.

[48] Richmond, A. (2002) NF- $\mathrm{KB}$, chemokine gene transcription and tumour growth. Nat Rev Immunol, 2, 664-674

[49] Balkwill, F. (2004) Cancer and chemokine network. Nat Rev Cancer, 4, 540-550.

[50] Hussain, T.; M Gupta, S. and Mukhtar, H. (2003) Cyclooxygenase2 and prostate carcinogenesis. Cancer Lett, 191, 125-135.

[51] Hussain, S.P.; He, P.; Subleski, J.; Hofseth, L.J.; Trivers, G.E.; Mechanic, L.; Hofseth, A.B.; Bernard, M.; Schwank, J.; Nguyen, G.; Mathe, E.; Djurickovic, D.; Haines, D.; Weiss, J.; Back, T.; Gruys, E.; Laubach, V.E., Wiltrout, R.H. and Harris, C.C. (2008) Nitric oxide is a key component in inflammation-accelerated tumorigenesis. Cancer Res. 68, 7130-6.

[52] Wang, J.; Torbenson, M.; Wang, Q.; Ro, J.Y. and Becich, M. (2003) Expression of inducible nitric oxide synthase in paired neoplastic and non neoplastic primary prostate cell cultures and prostatectomy specimens. Urol Oncol, 21, 117-122.

[53] Rocconi, R.P.; Kirby, T.O.; Seitz, R.S.; Beck, R.; Straughn, J.M. J; Alvarez, R.D. and Huh, W.K. (2008) Lipoxygenase pathway receptor expression in ovarian cancer. Reprod Sci., 15, 321-6.

[54] Lippitz, B.E., (2013) Cytokine patterns in patient with cancer: a systematic review. Lancet, 14, e218-e228

[55] Strieter, R.M. (2005) Masters of angiogenesis. Nat Med, 11, 925927.

[56] Ezashi, T.; Das, P. and Roberts, R.M. (2005) Low O2 tension and prevention of differentiated hES cells. Proc Natl Acad Sci U S A., 102, 4783-88.

[57] Di Lorenzo, G.; Tortora, G.; D’Armiento, F.P.; De Rosa, G.; Staibano, S.; Autorino, R.; D’Armiento, M.; De Laurentiis, M.; De Placido, S.; Catalano, G.; Bianco, A.R. and Ciardiello, F. (2002) Expression of epidermal growth factor receptor correlates with disease relapse andprogression to androgen-independence in human prostatecancer. Clin Cancer Res, 8, 3438-3444.

[58] Hiratsuka, S.; Watanabe, A.; Sakurai, Y.; Akashi-Takamura, S.; Ishibashi, S.; Kiyake, K.; Shibuya, M.; Akira, S.; Aburatani, H. and Maru, Y. (2008) The S100A8-serum amyloid A3-TLR4 paracrine cascade establishes a pre-metastatic cascade. Nat Cell Biol, 10, 1349-55.

[59] Gabay, C. and Kushner, I. (1999) Acute-phase proteins and other systemic responses to inflammation. NEJM, 340, 448-454.

[60] Deban, L.; Bottazzi, B.; Garlanda, C.; de la Torre, Y.M. and Mantovani, A. (2009) Pentraxins: multifunctional proteins at the interface of innate immunity and inflammation. Biofactors, 35, 138-45.

[61] Tafani, M.; De Santis, E.; Coppola, L.; Perrone, G.A.; Carnevale, I.; Russo, A.; Pucci, B.; Carpi, A.; Bizzarri, M. and Russo, M.A. (2014) Bridging hypoxia, inflammation and estrogen receptors in thyroid cancer progression. Biomed Pharmacother, 68, 1-5.

[62] De Santis, E.; Di Vito, M.; Perrone, G.A.; Mari, E.; Osti, M.; De Antoni, E.; Coppola, L.; Tafani, M.; Carpi, A. and Russo, M.A. (2013) Overexpression of pro-inflammatory genes and downregulation of SOCS-1 in human PTC and in hypoxic BCPAP cells. Biomed Pharmacother, 67, 7-16.

[63] Anzai, T. (2013) Post-infarction inflammation and left ventricular remodeling: a double-edged sword. Circ J., 77, 580-7.

[64] Volz, H.C.; Kaya, Z.; Katus, H.A. and Andrassy, M. (2010) The role of HMGB1/RAGE in inflammatory cardiomyopathy. Semin Thromb Hemost., 36, 185-194.

[65] Frangogiannis, N.G.; Smith, C.W. and Entman, M, L, (2002) The inflammatory response in myocardial infarction. Cardiovasc Res., 53, 31-47.
[66] Brea, D.; Sobrino, T.; Ramos-Cabrer, P. and Castillo, J. (2009) Inflammatory and neuroimmunomodulatory changes in acute cerebral ischemia. Cerebrovasc Dis., 27 - Suppl 1, 48-64.

[67] Iadecola, C. and Anrather, J. (2011) The immunology of stroke: from mechanisms to translation Nat Med., 17, 796-808.

[68] Courties, G.; Moskowitz, M.A. and Nahrendorf, M. (2014) The innate immune system after ischemic injury: lessons to be learned from the heart and brain. JAMA Neurol., 71, 233-236.

[69] Becker, K. (2012) Autoimmune responses to brain following stroke. Transl Stroke Res., 3, 310-7.

[70] Ye, J. (2011) Adipose tissue vascularization: its role in chronic inflammation. Curr Diab Rep, 11, 203-10.

[71] He, Q.; Gao, Z.; Yin, J.; Zhang, J.; Yun, Z. and Ye, J. (2011) Regulation of HIF-1 \{alpha\} activity in adipose tissue by obesityassociated factors: adipogenesis, insulin, and hypoxia. $\mathrm{Am} \mathrm{J}$ Physiol Endocrinol Metab, 300, E877-85.

[72] Ye, J. (2009) Emerging role of adipose tissue hypoxia in obesity and insulin resistance. Int $J$ Obes (Lond), 33, 54-66.

[73] Caspar-Bauguil, S.; Cousin, B.; Bour, S.; Casteilla, L.; Penicaud, L. and Carpéné, C. (2009) Adipose tissue lymphocytes: types and roles. $J$ Physiol Biochem, 65, 423-36.

[74] Odegaard, J.I. and Chawla, A. (2013) Pleiotropic actions of insulin resistance and inflammation in metabolic homeostasis. Science, 339, $172-7$.

[75] Miyata, T. and de Strihou, C.v. (2010) Diabetic nephropathy: a disorder of oxygen metabolism? Nat Rev Nephrol, 6, 83-95.

[76] Singh, V.P.; Bali, A.; Singh, N. and Jaggi, A.S. (2014) Advanced glycation end products and diabetic complications. Korean $J$ PhysiolPharmacol, 18, 1-14.

[77] Gugliucci, A. and Menini, T. (2014) The Axis AGE-RAGESoluble RAGE and Oxidative Stress in Chronic Kidney Disease. Adv Exp Med Biol, 824, 191-208.

[78] Winne, J. and Braunwald, E. (2008) Cardiomyopathies and myocarditis In "Harrison's Principles of Internal Medicine" Chpt 231, 1481-1488 Fauci A et al Edts, McGraw-Hill, NY.

[79] Frey, N. and Olson, E.N, (2003) Cardiac Hypertrophy: The Good, the Bad, and the Ugly Annu. Rev. Physiol., 65, 45-79.

[80] Frustaci, A., Russo, M.A. and Chimenti, C. (2013) Diagnostic contribution of left ventricular endomyocardial biopsy in patients with clinical phenotype of hypertrophic cardiomyopathy. Hum Pathol, 44, 133-41.

[81] Gross, D.A. and Silver, D.L. (2014) Cytosolic lipid droplets: From mechanisms of fat storage to disease. Crit Rev BiochemMolBiol, 49, 304-26.

[82] Segatori, L. (2014) Impairment of homeostasis in lysosomal storage disorders. IUBMB Life, Jul 18. doi: 10.1002/iub.1288.

[83] Chimenti, C.; Morgante, E.; Tanzilli, G.; Mangieri, E.; Critelli, G.; Gaudio, C.; Russo, M.A. and Frustaci, A. (2008) Angina in Fabry Disease Reflects Coronary Small Vessel Disease. Circ Heart Fail., 1, 161-169.

[84] Santos, B.L.; de Souza, C.F.; Schuler-Faccini, L.; Refosco, L.; Epifanio, M.; Nalin, T.; Gonçalves, S.M. and Schwartz, I.V. (2014) Glycogen storage disease type I: clinical and laboratory profile. $J$ Pediatr (Rio J), Jul 11. pii: S0021-7557(14)00096-5.doi: 10.1016/ j.jped.2014.02.005.

[85] Pifl, C.; Rajput, A.; Reither, H.; Blesa, J.; Cavada, C.; Obeso, J.A.; Rajput, A.H. and Hornykiewicz, O. (2014) Is Parkinson's disease a vesicular dopamine storage disorder? Evidence from a study in isolated synaptic vesicles of human and nonhuman primate striatum. J Neurosci, 34, 8210-8.

[86] Platt, F.M. (2014) Sphingolipid lysosomal storage disorders. Nature, 510, 68-75.

[87] Matrone, C.; Djelloul, M.; Taglialatela, G. and Perrone, L. (2014) Inflammatory risk factors and pathologies promoting Alzheimer's disease progression: is RAGE the key? Histol Histopathol, Jul 11. [Epub ahead of print] PubMed PMID: 25014735.

[88] Brundin, P.; Melki, R. and Kopito, R. (2010) Prion-like transmission of protein aggregates in neurodegenerative diseases. Nat Rev Mol Cell Biol., 11, 301-7.

[89] Maeda, A.; Tamura, K.; Wakui, H.; Ohsawa, M.; Azushima, K.; Uneda, K.; Kanaoka, T.; Kobayashi, R.; Ohki, K.; Matsuda, M.; Tsurumi-Ikeya, Y.; Yamashita, A.; Tokita, Y. and Umemura, S. (2014) Effects of the Angiotensin receptor blocker olmesartan on adipocyte hypertrophy and function in mice with metabolic disorders. Biomed Res Int, 2014, 946492. 
[90] Chung, S.; Cuffe, H.; Marshall, S.M.; McDaniel, A.L.; Ha, J.H.; Kavanagh, K.; Hong, C.; Tontonoz, P.; Temel, R.E. and Parks, J.S. (2014) Dietary Cholesterol Promotes Adipocyte Hypertrophy and Adipose Tissue Inflammation in Visceral, but Not in Subcutaneous, Fat in Monkeys. Arterioscler Thromb Vasc Biol, Jun 26. pii:ATVBAHA.114.303896.

[91] Hollak, C.E. and Wijburg, F.A. (2014) Treatment of lysosomal storage disorders: successes and challenges. J Inherit Metab Dis, 37, 587-98.

[92] Adir, Y. and Harari, S. (2014) Pulmonary hypertension associated with chronic obstructive lung disease and idiopathic pulmonary fibrosis. Curr Opin Pulm Med, Jul 18. [Epub ahead of print] PubMed PMID: 25046428.

[93] Corridoni, D.; Arseneau, K.O. and Cominelli, F. (2014) Inflammatory bowel disease. Immunol Lett, Jun 2. pii: S01652478(14)00073-X

[94] Neubauer, J.A. and Sunderram, J. (2012) Heme oxygenase-1 and chronic hypoxia. Respir Physiol Neurobiol, 184, 178-85.

[95] Brieger, K.; Schiavone, S.; Miller, F.J. Jr and Krause, K.H. (2012) Reactive oxygen species: from health to disease. Swiss Med Wkly, 142, w13659.

[96] Siomek, A. (2012) NF-кB signaling pathway and free radical impact. Acta Biochim Pol, 59, 323-31.

[97] Ponugoti, B.; Dong, G. and Graves, D.T. (2012) Role of forkhead transcription factors in diabetes-induced oxidative stress. Exp Diabetes Res, 2012, 939751.

[98] Spiro, S. (2012) Nitrous oxide production and consumption: regulation of gene expression by gas-sensitive transcription factors. Philos Trans R Soc Lond B BiolSci, 367, 1213-25.

[99] Brunet, A. and Berger, S.L. (2014) Epigenetics of aging and agingrelated disease. J Gerontol A Biol Sci Med Sci, 69, S17-20.

[100] Kolovou, G.D.; Kolovou, V. and Mavrogeni, S. We Are Ageing. (2014) Biomed Res Int, 2014, 808307

[101] Joyner, M.J. (2014) Buying into healthy blood vessels: exercise and aging. J Appl Physiol (1985), Jul 3. pii: jap.00474.2014.

[102] Semenza, G.L. (2012). Hypoxia-inducible factors: mediators of cancer progression and targets for cancer therapy. Trends PharmacolSci, 33, 207-14.

[103] Xia, Y.; Choi, H.K. and Lee, K. (2012). Recent advances in hypoxia-inducible factor (HIF)-1 inhibitors. Eur J Med Chem, 49, 24-40.

[104] Jiang, B.H.; Jiang, G.; Zheng, J.Z.; Lu, Z.; Hunter, T. and Vogt PK. (2001). Phosphatidylinositol 3-kinase signaling controls levels of hypoxia-inducible factor 1. Cell Growth Differ, 12, 363-9.

[105] Majumder, P.K.; Febbo, P.G.; Bikoff, R.; Berger, R.; Xue, Q.; McMahon, L.M.; Manola, J.; Brugarolas, J.; McDonnell, T.J.; Golub, T.R.; Loda, M.; Lane, H.A. and Sellers, W.R. (2004). mTOR inhibition reverses Akt-dependent prostate intraepithelial neoplasia through regulation of apoptotic and HIF-1-dependent pathways. Nat Med, 10, 594-601.

[106] Mabjeesh, N.J.; Escuin, D.; LaVallee, T.M.; Pribluda, V.S.; Swartz, G.M.; Johnson, M.S.; Willard, M.T.; Zhong, H.; Simons, J.W. and Giannakakou, P. (2003). 2ME2 inhibits tumor growth and angiogenesis by disrupting microtubules and dysregulating HIF. Cancer Cell, 3, 363-75

[107] Yoon, H.; Shin, S.H.; Shin, D.H.; Chun, Y.S. and Park, J.W. (2014) Differential roles of Sirt1 inHIF-1 $\alpha$ and HIF-2 $\alpha$ mediated hypoxic responses. Biochem Biophys Res Commun, 444, 36-43.

[108] Seo, K.S.; Park, J.H.; Heo, J.Y.; Jing, K.; Han, J.; Min, K.N.; Kim, C.; Koh, G.Y.; Lim, K.; Kang, G.Y.; Uee Lee, J.; Yim, Y.H.; Shong, M.; Kwak, T.H. and Kweon, G.R. (2014) SIRT2 regulates tumour hypoxia response by promoting HIF-1 $\alpha$ hydroxylation. Oncogene, Mar 31. doi:10.1038/onc.2014.76.

[109] Haigis, M.C.; Deng, C.X.; Finley, L.W.; Kim, H.S. and Gius, D. (2012) SIRT3 is a mitochondrial tumor suppressor: a scientific tale that connects aberrant cellular ROS, the Warburg effect, and carcinogenesis. Cancer Res, 72, 2468-72.

[110] Pellegrini, L.; Pucci, B.; Villanova, L.; Marino, M.L.; Marfe, G.; Sansone, L.; Vernucci, E.; Bellizzi, D.; Reali, V.; Fini, M.; Russo, M.A. and Tafani, M. (2012). SIRT3 protects from hypoxia and staurosporine-mediated cell death by maintaining mitochondrial membrane potential and intracellular pH. Cell Death Differ, 19, 1815-25.

[111] Choi, H.; Chun, Y.S.; Kim, S.W.; Kim, M.S and Park, J.W. (2006). Curcumin inhibits hypoxia inducible factor-1 by degrading aryl hydrocarbon receptor nuclear translocator: a mechanism of tumor growth inhibition. Mol Pharmacol, 70, 1664-71.

[112] Dat, N.T.; Jin, X.; Lee, K.; Hong, Y.S.; Kim, Y.H. and Lee, J.J. (2009). Hypoxia-inducible factor-1 inhibitory benzofurans and chalcone-derived diels-alder adducts from Morus species. $J$ Nat Prod, 72, 39-43.

[113] Park, S.Y.; Jeong, K.J.; Lee, J.; Yoon, D.S.; Choi, W.S.; Kim, Y.K.; Han, J.W.; Kim, Y.M.; Kim , B.K. and Lee, H.Y. (2007) Hypoxia enhances LPA-induced HIF-1alpha and VEGF expression: their inhibition by resveratrol. Cancer Lett, 258, 63-9.

[114] Liu, Y.; Veena, C.K.; Morgan, J.B.; Mohammed, K.A.; Jekabsons, M.B.; Nagle, D.G. and Zhou, Y.D. (2009). Methylalpinumisoflavone inhibits hypoxia-inducible factor-1 (HIF-1) activation by simultaneously targeting multiple pathways. J Biol Chem, 284, 5859-68

[115] Dat, N.T.; Jin, X.; Lee, J.H.; Lee, D.; Hong, Y.S.; Lee, K.; Kim, Y.H. and Lee, J.J. (2007) Abietanediterpenes from Salvia miltiorrhiza inhibit the activation of hypoxia-inducible factor-1. $J$ Nat Prod, 70, 1093-7.

[116] Lee, K.; Zhang, H.; Qian, D.Z.; Rey, S.; Liu, J.O. and Semenza, G.L. (2009). Acriflavine inhibits HIF-1 dimerization, tumor growth, and vascularization. Proc Natl Acad Sci US A, 106, 17910-5.

[117] Tanaka, T.; Yamaguchi, J.; Shoji, K. and Nangaku, M. (2012). Anthracycline Inhibits Recruitment of Hypoxia-inducible Transcription Factors and Suppresses Tumor Cell Migration and Cardiac Angiogenic Response in the Host. J Biol Chem, 287, 34866-82.

[118] Befani, C.D.; Vlachostergios, P.J.; Hatzidaki, E.; Patrikidou, A.; Bonanou, S.; Simos, G.; Papandreou, C.N. and Liakos, P. (2012) Bortezomib represses HIF-1 $\alpha$ protein expression and nuclear accumulation by inhibiting both PI3K/Akt/TOR and MAPK pathways in prostate cancer cells. J Mol Med (Berl), 90, 45-54.

[119] Kung, A.L.; Zabludoff, S.D.; France, D.S.; Freedman, S.J.; Tanner, E.A.; Vieira, A.; Cornell-Kennon, S.; Lee, J.; Wang, B.; Wang, J.; Memmert, K.; Naegeli, H.U.; Petersen, F.; Eck, M.J.; Bair, K.W.; Wood, A.W. and Livingston, D.M. (2004). Small molecule blockade of transcriptional coactivation of the hypoxia-inducible factor pathway. Cancer Cell, 6, 33-43.

[120] Yang, D.; Wei, F.; Tewary, P.; Howard, O.M. and Oppenheim, J.J. (2013) Alarmin-induced cell migration. Eur J Immunol, 43, 1412-8.

[121] Alexiou, P.; Chatzopoulou, M.; Pegklidou, K. and Demopoulos, V.J. (2010) RAGE: a multi-ligand receptor unveiling novel insights in health and disease. Curr Med Chem, 17, 2232-52.

[122] Yamagishi, S.; Nakamura, K.; Matsui, T.; Ueda, S.; Fukami, K. and Okuda, S. (2008) Agents that block advanced glycation end product (AGE)-RAGE (receptor for AGEs)-oxidative stress system: a novel therapeutic strategy for diabetic vascular complications. Expert Opin Investig Drugs, 17, 983-96.

[123] Yan, S.F.; Ramasamy, R. and Schmidt, A.M. (2010) Soluble RAGE: therapy and biomarker in unraveling the RAGE axis in chronic disease and aging. Biochem Pharmacol, 79, 1379-86.

[124] Puddu, A.; Mach, F.; Nencioni, A.; Viviani, G.L. and Montecucco, F. (2013) An emerging role of glucagon-like peptide-1 in preventing advanced-glycation-end-product-mediated damages in diabetes. Mediators Inflamm, 2013:591056. doi:10.1155/2013/ 591056.

[125] Bahner, J.D. and Bordeaux, J.S. (2013) Non-melanoma skin cancers: photodynamic therapy, cryotherapy, 5-fluorouracil, imiquimod, diclofenac, or what? Facts and controversies. Clin Dermatol, 31, 792-8.

[126] Hennessy, E.J.; Parker, A.E. and O'Neill, L.A. (2010) Targeting Toll-like receptors: emerging therapeutics? Nat Rev Drug Discov, 9, 293-307.

[127] O'Neill, L.A.; Bryant, C.E. and Doyle, S.L. (2009) Therapeutic targeting of Toll-like receptors for infectious and inflammatory diseases and cancer. Pharmacol Rev, 61, 177-97.

[128] Krieg, A.M. (2008) Toll-like receptor 9 (TLR9) agonists in the treatment of cancer.Oncogene, 27, 161-7.

[129] Köchling, J.; Prada, J.; Bahrami, M.; Stripecke, R.; Seeger, K.; Henze, G.; Wittig, B. and Schmidt, M. (2008) Anti-tumor effect of DNA-based vaccination and dSLIM immunomodulatory molecules in mice with $\mathrm{Ph}+$ acute lymphoblastic leukaemia. Vaccine, 26, 4669-75.

[130] D'Agostini, C.; Pica, F.; Febbraro, G.; Grelli, S.; Chiavaroli, C. and Garaci, E. (2005) Antitumour effect of OM-174 and 
cyclophosphamide on murine B16 melanoma in different experimental conditions. IntImmunopharmacol, 5, 1205-12.

[131] Murata, M. (2008) Activation of Toll-like receptor 2 by a novel preparation of cell wall skeleton from Mycobacterium bovis BCG Tokyo (SMP-105) sufficiently enhances immune responses against tumors. Cancer Sci, 99, 1435-40.

[132] Mark, K.E.; Corey, L.; Meng, T.C.; Magaret, A.S.; Huang, M.L.; Selke, S.; Slade, H.B.; Tyring, S.K.; Warren, T.; Sacks, S.L.; Leone, P.; Bergland, V.A. and Wald, A. (2007) Topical resiquimod $0.01 \%$ gel decreases herpes simplex virus type 2 genital shedding: a randomized, controlled trial. J Infect Dis, 195, 1324-31.

[133] Kronenberger, B. and Zeuzem, S. (2012) New developments in HCV therapy. $J$ Viral Hepat, 19Suppl 1:48-51.

[134] Sun, S.; Rao, N.L.; Venable, J.; Thurmond, R. and Karlsson, L. (2007) TLR7/9 antagonists as therapeutics for immune-mediated inflammatory disorders. Inflamm Allergy Drug Targets, 6, 223-35.

[135] Parkinson, T. (2008) The future of toll-like receptor therapeutics. Curr Opin Mol Ther, 10, 21-31.

[136] Ungaro, R.; Fukata, M.; Hsu, D.; Hernandez, Y.; Breglio, K.; Chen, A.; Xu, R.; Sotolongo, J.; Espana, C.; Zaias, J.; Elson, G.; Mayer, L.; Kosco-Vilbois, M. and Abreu, M.T. (2009) A novel Toll-like receptor 4 antagonist antibody ameliorates inflammation but impairs mucosal healing in murine colitis. Am J Physiol Gastrointest Liver Physiol, 296, G1167-79.

[137] Lamkanfi, M. (2011) Emerging inflammasome effector mechanisms. Nat Rev Immunol, 11, 213-20.

[138] Moll, M. and Kuemmerle-Deschner, J.B. (2013) Inflammasome and cytokine blocking strategies in autoinflammatory disorders. ClinImmunol, 147, 242-75.

[139] Hedrich, C.M.; Bruck, N.; Fiebig, B. and Gahr, M. (2012) Anakinra: a safe and effective first-line treatment in systemic onset juvenile idiopathic arthritis (SoJIA).Rheumatol Int, 32, 3525-30.

[140] Zhao, J.; Wang, H.; Dai, C.; Wang, H.; Zhang, H.; Huang, Y.; Wang, S.; Gaskin, F.; Yang, N. and Fu, S.M. (2013) P2X7 blockade attenuates murine lupus nephritis by inhibiting activation of the NLRP3/ASC/caspase 1 pathway. Arthritis Rheum, 65, 317685.

[141] Juliana, C.; Fernandes-Alnemri, T.; Wu, J.; Datta, P.; Solorzano, L.; Yu, J.W.; Meng, R.; Quong, A.A.; Latz, E.; Scott, C.P and Alnemri, E.S. (2010) Anti-inflammatory compounds parthenolide and Bay 11-7082 are direct inhibitors of the inflammasome. $J$ Biol Chem, 285, 9792-802.

[142] Gupta, S.C.; Sundaram, C.; Reuter, S. and Aggarwal, B.B. (2010). Inhibiting NF- $\mathrm{BB}$ activation by small molecules as a therapeutic strategy. Biochim Biophys Acta, 1799, 775-87.

[143] Karin, M.; Yamamoto, Y. and Wang, Q.M. (2004). The IKK NFkappa B system: a treasure trove for drug development. Nat Rev Drug Discov, 3, 17-26

[144] Lubbad, A.; Oriowo, M.A. and Khan, I. (2009). Curcumin attenuates inflammation through inhibition of TLR-4 receptor in experimental colitis. Mol Cell Biochem, 322, 127-35.

[145] Kast, R.E. (2006). Aspirin, TNF-alpha, NFkB, and survival in multiple myeloma: the importance of measuring TNF-alpha. Inflammopharmacology, 14, 256-9.

[146] Sreenivasan, Y., Sarkar, A. and Manna, S.K. (2003). Mechanism of cytosine arabinoside-mediated apoptosis: role of Rel A (p65) dephosphorylation. Oncogene, 22, 4356-69.

[147] Kale, A.J. and Moore, B.S. (2012). Molecular Mechanisms of Acquired Proteasome Inhibitor Resistance. J Med Chem, 55, 10317-27.

[148] Wilczynski, J.; Duechler, M. and Czyz, M. (2011). Targeting NF$\kappa \mathrm{B}$ and HIF-1 pathways for the treatment of cancer: part I. Arch Immunol Ther Exp (Warsz), 59, 289-99.

[149] Gray, S.G. and Teh, B.T. (2001). Histone acetylation/deacetylation and cancer: an "open" and "shut" case? Curr Mol Med, 1, 401-29.

[150] Kozakai, N.; Kikuchi, E.; Hasegawa, M.; Suzuki, E.; Ide, H.; Miyajima, A.; Horiguchi, Y.; Nakashima, J.; Umezawa, K.; Shigematsu, N. and Oya, M. (2012). Enhancement of radiosensitivity by a unique novel $\mathrm{NF}-\kappa \mathrm{B}$ inhibitor, DHMEQ, in prostate cancer. Br J Cancer, 107, 652-7. 